\title{
Identifying Key Factors for the Implementation and Maintenance of Green Stormwater Infrastructure
}

\author{
Zack L. DelGrosso
}

Thesis submitted to the faculty of the Virginia Polytechnic Institute and State University in partial fulfillment of the requirements for the degree of

Master of Science

In

Civil Engineering

Randel L. Dymond, Chair

Clayton C. Hodges

Kevin D. Young

May 4, 2018

Blacksburg, VA

Keywords: green stormwater infrastructure, stormwater management, construction, maintenance, best management practice 


\title{
Identifying Key Factors for the Implementation and Maintenance of Green Stormwater Infrastructure
}

\author{
Zack L. DelGrosso
}

\section{ACADEMIC ABSTRACT}

Construction and maintenance can have huge implications on the long-term functioning of GSI facilities. GSI facilities investigated were bioretention, permeable pavement, sand filters, infiltration trenches, and vegetated swales. This study first highlights the most important construction and maintenance items based on relevant studies and state stormwater manuals. Fairfax County, VA was used as a case study to evaluate the County's current stormwater program and illuminate common maintenance issues found for each GSI type. Data analysis of 3141 inspection records illustrated particular deficiencies for each GSI type and that there are differences between public and private facilities, most likely depending on site conditions and frequency of routine maintenance. Sediment accumulation was found to be the most common maintenance issue (27.8\% of inspections), supporting the importance of adequate pretreatment and good housekeeping when implementing GSI. The Northern Virginia Soil and Water Conservation District (NVSWCD) performed a study surveying 63 public bioretention facilities in which they measured ponding depth, filter media depth, ponding area, and infiltration rates. The NVSWCD concluded that deficiencies found in facilities could mostly be attributed to inadequacies during construction. By comparing current post-construction inspections performed by the County to the NVSWCD data, it was found that these County inspections are failing to detect these inadequacies in bioretention facilities from improper construction. It is recommended that MS4s thoroughly record and track construction and post-construction inspection items to improve the longevity of its facilities and better inform future decision making regarding GSI. 


\section{Identifying Key Factors for the Implementation and Maintenance of Green Stormwater Infrastructure}

Zack L. DelGrosso

\section{GENERAL AUDIENCE ABSTRACT}

Studies have shown that the proper construction and maintenance of green stormwater infrastructure (GSI) is a critical factor concerning its long-term performance; however, little research has been conducted on the necessary protocols and frequency to ensure its longevity. Many MS4s and stormwater managers are implementing these facilities without providing the adequate institutional framework to ensure the proper construction and maintenance. This study concentrates on illuminating the construction and maintenance factors critical for the performance of GSI. Facility types investigated were bioretention, permeable pavement, sand filters, infiltration trenches, and vegetated swales. The effects of local site-conditions and level of routine maintenance on frequency of facility deficiencies was quantified using 3141 records of maintenance and inspection data from Fairfax County, VA. Sediment and debris accumulation were found to be the most common deficiency highlighting the importance of good housekeeping and pretreatment devices. The Northern Virginia Soil and Water Conservation District (NVSWCD) performed a comprehensive review of 63 bioretention facilities in which they inspected elements considered critical to pollutant removal performance including ponding depth, filter media depth, and infiltration rates. By comparing the findings from the NVSWCD to current post-construction inspections performed by the County, it was found that current inspection protocols are missing important design components of bioretention facilities. This study also highlights the importance of thorough and thoughtful databases to track and record inspection and maintenance data surrounding GSI. The proper construction and maintenance of GSI is ultimately dependent on a multitude of factors including site-conditions, facility design specifications, and institutional support. 


\section{ACKNOWLEDGEMENTS}

There are so many people that need to be thanked for their support and guidance throughout this thesis work. First and foremost, I must thank my committee advisor, Dr. Randel Dymond, for his support and belief in me to be a part of this wonderful research group. I came into Virginia Tech with no civil engineering background or even knowing the term 'hydrology'; only knowing that I wanted to learn how to help mitigate the impact of human development on the environment and surface waters. As fate would have it, Dr. Dymond was chosen to be my temporary advisor and after only a few minutes of looking over his research, I knew his group was the one I wanted to be a part of. After a year of learning the necessary background knowledge and proving myself as an engineer, he approached me with a simple offer. A desk in his graduate student offices. No funding. No assistance. Just a desk. This simple gesture is something I will never forget as it allowed me to meet my future colleagues and finally feel a part of the EWR graduate program. Being able to be a teaching assistant and be a part of a research group over the next three semesters is an experience I will cherish and it is something that would not have happened without the belief and support of Dr. Dymond.

The next people I must thank are the other two members of my committee, Dr. Clayton Hodges and Kevin Young. Clay was in the trenches with me throughout the thesis process providing his guidance and opinions every step of the way. I know I would not have survived this process without his guidance and expertise and for that I am so grateful. It was an honor to be able to TA Kevin's CEE 2814 Measurements Lab, as he was one of the most impressive instructors I have had here at Virginia Tech. His focus and demeanor towards life is something that I admire and strive for in mine. The support from these two individuals was invaluable.

Next I must thank my incredible colleagues (and now incredible friends) that I have had the

pleasure of working with. I want to thank Clint Martin for his support, guidance, and inspiration when I first joined the group and throughout my college career. I also must thank all of the distinguished members of the "slug club" - Amanda, Lauren, Meghan, and Melissa. It has been such a pleasure to work with these ladies and to grow with them as graduate students and as friends. The support and friendship from everyone I have me in the EWR graduate program is something that I will never forget. 
Lastly, I must thank my friends and family who have given me support all the way up to this point. To my Mom and Dad for helping support me, financially and emotionally, throughout my college career. To my late grandfather, Zack Bettis, for supporting me to earning my Bachelors from the University of Mary Washington. And to my late grandmother, Louise DelGrosso, for her support and love as I started my career here at Virginia Tech. I could not have done this without these incredible people in my life. 


\section{Table of Contents}

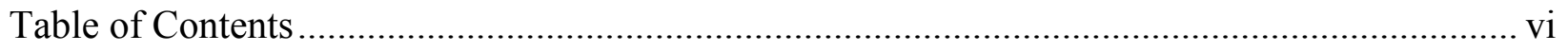

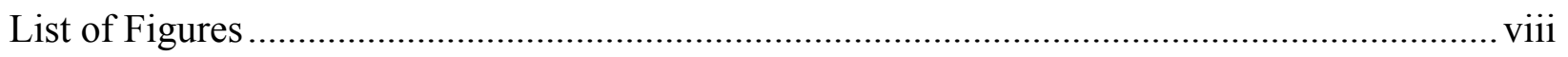

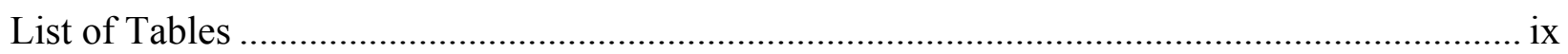

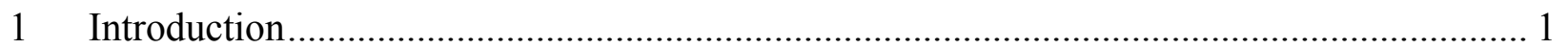

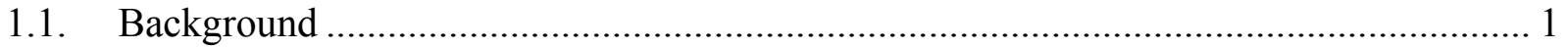

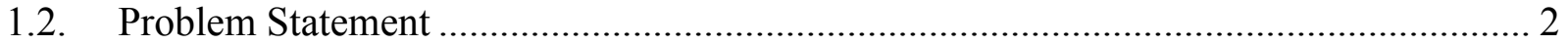

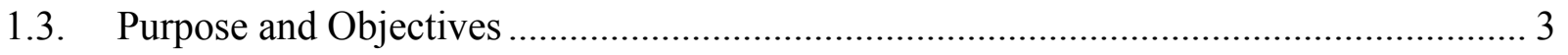

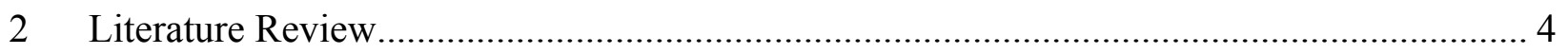

2.1. Effects of Urbanization on Water Quality.............................................................. 4

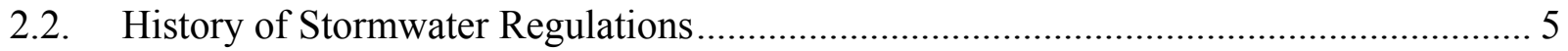

2.3. Implementation of Green Stormwater Infrastructure ............................................ 6

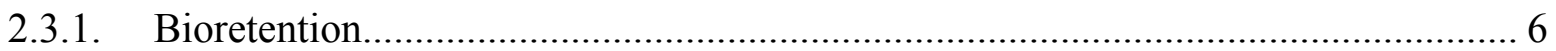

2.3.2. Infiltration Trench ..................................................................................... 7

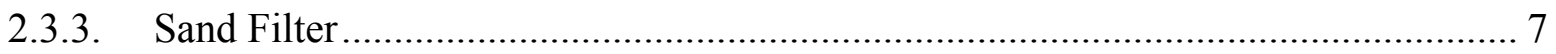

2.3.4. Permeable Pavement ................................................................................... 7

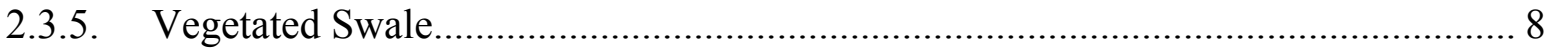

2.4. Construction and Maintenance of Green Stormwater Infrastructure ............................ 8

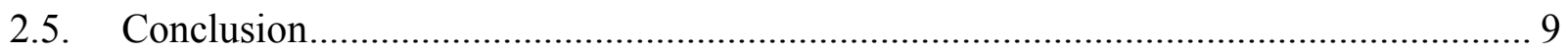

3 Identifying Key Factors for the Implementation and Maintenance of Green Stormwater

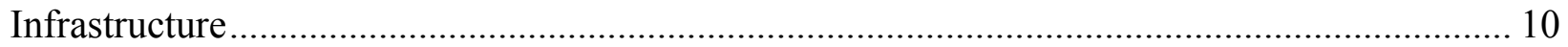

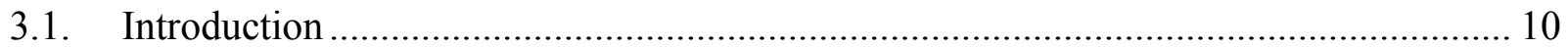

3.2. Literature Review: Construction and Maintenance Inspection Guidelines.................. 13

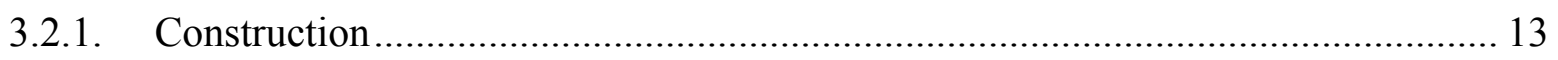

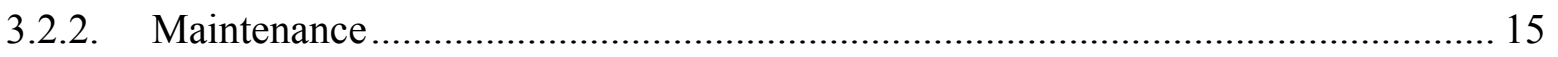

3.3. Case Study: Fairfax County’s GSI Maintenance Program....................................... 20

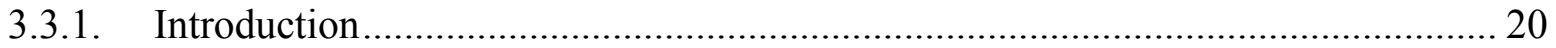

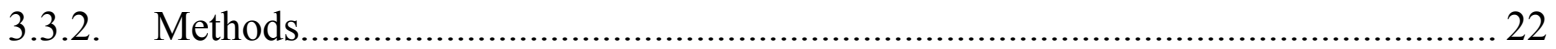

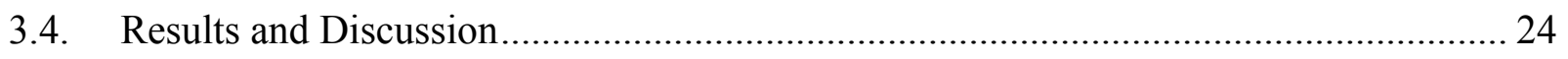

3.4.1. Maintenance Deficiency Frequency: Public vs. Private Facilities....................... 24

3.4.2. Bioretention Facilities: Comparing Inspection Findings .................................. 29

3.4.3. Correlation Between Inspection and NVSWCD Scores ..................................... 32 
3.5. Conclusions and Implications

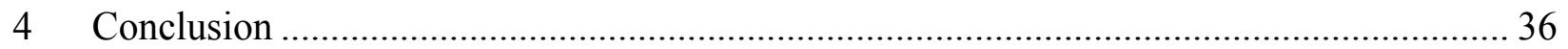

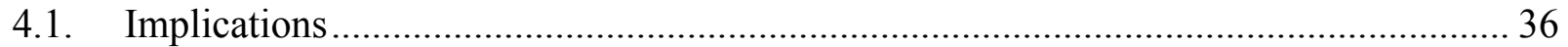

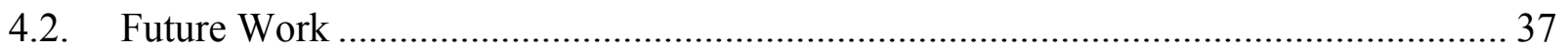

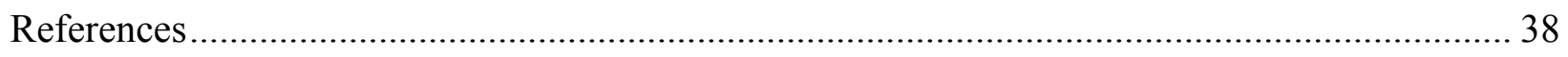

Appendix A - Fairfax Bioretention Inspection Checklist Items........................................... 45 


\section{List of Figures}

Figure 3.1 - Percent (\%) of inspection problems reported for (a) permeable pavement (PP), (b) infiltration trench (TR), (c) sand filter (SF), (d) vegetated swale (VS), (e) bioretention (BR) .... 27

Figure 3.2 - Inspection severity scores for inspection items from Fairfax County bioretention

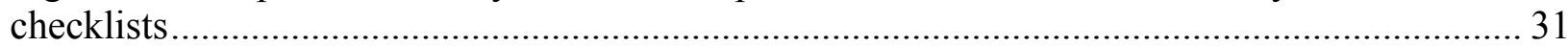

Figure 3.3 - Most frequently occurring inspection items from Fairfax County bioretention

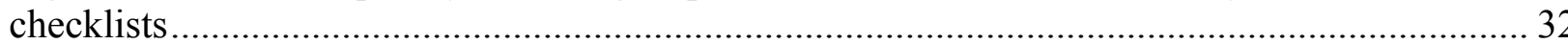

Figure 3.4 - Determining correlation between County inspection scores and NVSWCD scores. 33

Figure A.1 - Bioretention inspection checklist components and their inspection items..........45 


\section{List of Tables}

Table 3.1 - Fairfax County GSI facility counts for bioretention (BR), permeable pavement (PP), sand filter (SF), infiltration trench (TR), and vegetated swale (VS)

Table 3.2 - Common maintenance categories used to compare publicly and privately owned facilities

Table 3.3 - GSI inspection item frequencies (\%) for public versus private facilities reporting the number of inspections and various categories of maintenance deficiencies found during inspection 


\section{Introduction}

\subsection{Background}

Over recent decades, the focus of urban stormwater management has shifted to improving water quality in conjunction with flood mitigation, in order to meet increasing regulations centered around maintaining the chemical, biological, and physical integrity of the country's water (Environmental Law Institute 2013). Starting in the 1990s, local governments and owners of municipal separate storm sewer systems (MS4s) are now required to implement stormwater management plans to comply with new stormwater regulations centered around mitigating pollution from non-point sources (National Research Council 2008). One of the most common methods in which MS4s have chosen to meet these regulations is through the use of stormwater control measures (SCMs), also known as stormwater best management practices (BMPs). BMPs cover a wide range of activities, from non-structural methods such as educational programs and street sweeping programs (Urbonas 1994), to structural practices such as retention ponds and bioretention cells aimed at treating on-site runoff (Livingston et al. 1997). These structural BMPs, also known as green stormwater infrastructure (GSI), reduce runoff volume and can improve the water quality of runoff through physical removal (e.g. infiltration, settling), filtration, physio-chemical (e.g. adsorption), and biological (e.g. plant uptake) removal processes (Scholes et al. 2008). Structural BMPs are often utilized by MS4s because of their defined pollutant and volume reduction capabilities (Strecker et al. 2001; VA DCR 1999).

These defined pollutant removal metrics help MS4s clearly demonstrate to governmental agencies that they are meeting the necessary requirements of their stormwater permits. However, a regulatory stipulation of using GSI to meet water quality standards is to "ensure adequate longterm operation and maintenance of controls," meaning local governments and MS4s must put in place programs to ensure the longevity of these systems (US EPA 2005). Many studies have shown that proper construction and subsequent maintenance are critical factors for this longevity (Blecken et al. 2017; Brown and Hunt 2012; Roy-poirier et al. 2010). Compounding this fact, GSI facilities are more susceptible to problems due to improper construction and maintenance compared to traditional stormwater management facilities (Livingston et al. 1997). The specifics on the appropriate inspection frequency and protocols for the construction and maintenance of 
these facilities still requires more research. This places MS4s in the precarious position of having to allocate resources to ensure the proper construction, inspection, and maintenance of GSI without having definitive standards in place.

\subsection{Problem Statement}

The proper construction, maintenance, and implementation of GSI varies between regions and even between local-site conditions. This fact demonstrates the inherent difficulty in constructing and maintaining GSI at the scale of MS4s. Despite this, these facilities can provide valuable water quality and environmental impacts when properly installed and maintained (Blecken et al. 2017). Innovative technologies like these will be imperative to protect the environment as the rate of human development continues.

The specific construction and maintenance protocols critical for GSI performance are not fully understood and require more research. The swift adoption of GSI practices around the country has outpaced the requisite research and information necessary to ensure their effectiveness. This has caused localities to use information, design guidelines, and implementation protocols that may not be appropriate for the region or local-site conditions (Davis et al. 2009). At the same time, the level of training and certification that is required by contractors and inspectors is inconsistent, potentially affecting the quality of construction and long-term functionality of these facilities. Ultimately, the design and implementation of GSI varies across the country making it difficult to determine which construction and maintenance practices are most effective (National Research Council 2008).

The current regulatory framework of stormwater management and nonpoint source pollution is clearly pointing towards the continued use of GSI. This will require further capital investment in the construction and maintenance of these facilities, adding economic burdens on private developers and MS4s. With this in mind, it will be critical to increase the understanding of how the construction and maintenance of GSI can affect its performance in order to reduce capital resources wasted and ensure water quality standards are being met. 


\subsection{Purpose and Objectives}

This research concentrates on elucidating the construction factors and maintenance protocols that are critical for the long-term functionality and performance of GSI. GSI facilities to be investigated in this study include bioretention cells, permeable pavement, sand filters, infiltration trenches, and vegetated swales. In conjunction with relevant studies and standards, construction and maintenance inspection data from Fairfax County, Virginia will be used as a case study and used to assess the effectiveness of the current stormwater program used in the County. In addition, this data from Fairfax County will be used to determine the most common maintenance issues for each facility type. Several key factors will be identified and corresponding recommended improvements to construction and maintenance protocols regarding GSI will be proposed that will aid in maintaining the long-term performance of these systems. Specific objectives of this study include:

1) A review and comparison of the construction, inspection, and maintenance protocols associated with GSI in the United States.

2) Literature review of studies evaluating the effects of inadequate construction and/or maintenance on the functionality of GSI

3) Evaluation of Fairfax County's GSI construction, inspection, and maintenance procedures, records, and datasets as a case study.

4) Provide guidance to MS4s for the construction and maintenance of GSI. 


\section{Literature Review}

\subsection{Effects of Urbanization on Water Quality}

Urbanization results in the removal of vegetation, compaction of soil, and the transformation of pervious surfaces into impervious surfaces like buildings, roads, and sidewalks (Barbosa et al. 2012). This increase in impervious surfaces results in a host of effects on stormwater runoff characteristics and water resources. These effects include increased volume of stormwater runoff, increased peak flow rates produced during storm events, increased concentrations of pollutants (i.e. nutrients and sediment), and changes to stream morphology (Leopold 1968; Brabec et al. 2002; Walsh et al. 2005). Urbanization is the second major cause of stream impairment, only behind agriculture (Paul and Meyer 2001).

The increase in impervious surfaces alters flow paths and decreases the area of land available for water to infiltrate causing an increase in the runoff volume as well as peak flow rate (Leopold 1968). These effects are characteristically seen in a runoff hydrograph through a higher peak flow rate than predevelopment conditions. This peak is reached in a shorter amount of time due to a decreased time of concentration (US EPA 2000). In addition to this, the area under the curve (i.e. runoff volume) is greater for the post-development hydrograph.

Runoff can pick up pollutants and debris, common to urban environments, and carry them into local waterways negatively affecting water quality. High concentrations of nutrients such as nitrogen and phosphorous have been a primary concern to water quality and is the most common impairment of surface waters in the United States (Carpenter et al. 1998). Excess of these nutrients in waterways can lead to algal blooms and eutrophication, depleting the dissolved oxygen (DO) in the water column, and having detrimental effects on stream ecology (US EPA 1993). Increased sediment loads due to soil erosion from construction sites and other disturbed areas are another major pollutant of concern regarding surface water quality. Construction sites have extremely high erosion rates coupled with efficient drainage systems, leading to runoff containing sediment loads being several orders of magnitude higher than predevelopment conditions (Wolman and Schick 1967). Excess sediment can have adverse impacts on stream ecology including reducing the light penetration for use by producers as well as decreasing the species diversity of benthic macroinvertebrates and salmonids (Bilotta and Brazier 2008). 
The increased runoff volumes, flow rates, and sediment loads associated with urbanization can lead to negative changes in channel morphology. Increased flow rates and velocities of runoff can lead to accelerated erosion and scouring of streambanks causing the deepening and widening of channels (National Research Council 2008). Streambank erosion also increases the sediment load within a reach exacerbating the sediment loads downstream (US EPA 1993). This may cause downstream channels to fill with sediment, thereby changing the channel morphology into a more braided form. In general, urbanization leads to a reduction in channel complexity (i.e. simplified morphology) having significant effects on stream ecology (Walsh et al. 2005).

\subsection{History of Stormwater Regulations}

The shift in stormwater management regulations to include a focus on improving water quality began in 1972 with amendments to the Federal Water Pollution Control Act. These amendments are commonly referred to as the Clean Water Act (CWA) and were the first rigorous laws prohibiting discharges into the nation's waterways with the goal to restore and protect the chemical, physical, and biological integrity of the nation's waterways (James 2003). Initially, “discharges" were defined as discrete, point sources such as effluent from industrial and municipal wastewater discharges (National Research Council 2008). In order for these entities to discharge their effluent, they now had to obtain a National Pollution Discharge Elimination System (NPDES) permit to ensure the quality of effluent met specified standards. However, this left pollution due to non-point sources (i.e. stormwater) largely unabated (James 2003).

By the early 1980s, the regulation of point source pollution through the NPDES had shown significant advancement towards improving water quality. This success set the stage for the increased regulation and enforcement of water pollution contained within stormwater. The passing of additional amendments to the CWA in 1987 expanded the NPDES to include discharges from additional sources including industrial facilities, construction sites, and municipal separate storm sewer systems (MS4s). This change to the NPDES was implemented over two phases. Phase I, enacted in 1990, established stormwater permit rules for medium and large MS4s serving 100,000 or more people as well as construction sites of five or more acres. Phase II was implemented in 1999, applying the same regulations to smaller MS4s and construction activities down to one acre (National Research Council 2008). Permittees must reduce pollutants within stormwater runoff to the maximum extent practicable through the 
implementation of six minimum control measures which include: 1) public education and outreach, 2) public participation and involvement, 3) illicit discharge detection and elimination, 4) construction site runoff control, 5) management of post-construction site runoff, and 6) pollution prevention and good housekeeping (US EPA 2005b).

\subsection{Implementation of Green Stormwater Infrastructure}

Due to these increased regulations, qualifying MS4s must now show that they are reducing the discharge of pollutants from to the maximum extent practicable (US EPA 2016). One of the most common minimum control measures implemented in order to meet the conditions of MS4 permits is the management of post-construction site runoff. Structural stormwater best management practices (BMPs), also known as green stormwater infrastructure (GSI), have become a popular strategy to demonstrate this post-construction runoff control (Livingston et al. 1997). GSI facilities reduce runoff volume and remove pollutants through mechanisms such as settling, infiltration, and biological uptake through vegetation (US EPA 2005c). Each facility type is typically assigned runoff reduction and pollutant removal metrics, guiding the selection of appropriate facilities based on site-specific factors and goals of the MS4 (Scholes et al. 2008). Common GSI types include bioretention cells, infiltration trenches, sand filters, permeable pavement, and vegetated swales. Each of these facilities utilize different pollutant removal mechanisms and require unique design, construction, and maintenance considerations.

\subsubsection{Bioretention}

Bioretention was first developed in the early 1990's by the Prince George's County, MD, Department of Environmental Resources (US EPA 1999a). These facilities utilize a landscaped depression comprised of a filter media, surface mulch layer and vegetation designed to provide runoff reduction and improve water quality. Pollutant removal mechanisms include sedimentation, adsorption, filtration, volatilization, and storage capacity (Prince George's County 2002). Bioretention has become one of the most widely used GSI facilities because of their versatility and performance qualities (Brown and Hunt 2011). 


\subsubsection{Infiltration Trench}

Infiltration trenches are another common type of infiltration practice that incorporates some type of temporary storage (i.e. surface or underground) while allowing runoff to infiltrate into native soils. While treating runoff and reducing volume, these facilities can also be used to convey stormwater as an on-line facility to other GSI or storm sewers. Infiltration trenches typically are backfilled with some type of stone aggregate and sand layers (VA DEQ 2011a). The success of these facilities is dependent on accurately estimating the infiltration rates and necessary pretreatment (Livingston et al. 1997). Maintenance and construction considerations for these facilities are similar to any other type of infiltration practice. Infiltration trenches have been shown have a high risk to fail prematurely if not properly maintained (US EPA 1999a).

\subsubsection{Sand Filter}

Sand filters are a specific type of filtration practice that incorporates sand as a filter media in order to physically filter out sediments and other pollutants from runoff. Sand filters are popular because they provide a good balance between filtration rates and filtering efficiency (Urbonas 2002). Much like other GSI, sand filters can be designed to infiltrate into native soils or filter into an underdrain as an on-line facility (Portland Bureau of Environmental Services 2016). There are many types of sand filters around the country usually differentiated by being either "unconfined" or "confined" systems (Livingston et al. 1997). Though shown to be effective at reducing pollutant loads within runoff, maintenance burdens can be very intensive for sand filters (Urbonas 2002).

\subsubsection{Permeable Pavement}

The first application of permeable pavement was in the state of Florida in the 1970s in an attempt to meet stormwater retention requirements and improve water quality (Ferguson 2010). Permeable pavement systems have gained a lot of attention in recent years as they can reduce the pervious area on a site while providing a stable load-bearing surface. Permeable pavement can also promote groundwater recharge through infiltration and provide pollutant removal (NY DEC 2010). The performance of permeable pavement facilities has been shown to be highly variable. While some studies have touted their efficient pollutant removal and runoff reduction capabilities 
(Ferguson 2010), others describe failure rates as high as 75 percent (US EPA 1999b). It is agreed, however, that proper and timely maintenance is critical for the long-term performance of these facilities (Putman 2010).

\subsubsection{Vegetated Swale}

Vegetated swales are an alternative to traditional stormwater conveyance systems (i.e. storm sewers and curb and gutter) with the additional benefit of providing pollutant removal through sedimentation, infiltration, and filtration (US EPA 1999). These facilities are easy to design and can be used as a stand-alone or incorporated with other GSI within a treatment train. Vegetated swales have been shown to be limited in their applicability being vulnerable to high velocity flows and needing specific soil and topographic conditions to function properly (NJ DEP 2014a).

\subsection{Construction and Maintenance of Green Stormwater Infrastructure}

GSI requires more considerations during construction compared to traditional stormwater management facilities. Improper construction can significantly impact the intended runoff reduction and pollutant removal capabilities of a facility as well as reduce its long-term performance (Livingston et al. 1997). Studies have shown that deficiencies found in GSI facilities can often be attributed to improper construction techniques (Brown and Hunt 2010; NVSWCD 2017). Poor construction techniques have been shown to lead to preferential flow paths and diminished infiltration rates within bioretention facilities (Roy-poirier et al. 2010). The proper construction of GSI is centered around thoughtful construction sequencing, ensuring all parties involved know their responsibilities, protecting soils and media from compaction and clogging, properly installing filter media and aggregate, and ensuring facilities are kept off-line until the entire drainage area is stabilized. More generally, it is important for contractors to be aware of the sensitivity of GSI and for municipalities to ensure that facilities are being inspected by qualified inspectors at critical points.

The long-term performance of GSI facilities is highly dependent on adequate and timely postconstruction inspections and maintenance (Erickson et al. 2009). The most common cause of failure of GSI is the lack of adequate maintenance (Livingston et al.1997). Maintenance can typically be broken into different levels depending on the type, frequency, and intensity required. 
Routine maintenance is performed regularly, typically encompassing predictable tasks such as vegetation maintenance or debris removal. Non-routine maintenance is performed more infrequently and is typically in response to facility failures such as clogging or structural repairs. Major maintenance items would pertain to critical deficiencies that require partial or complete rebuilds of the facility (Kang et al. 2008; Erickson et al. 2009; Flynn et al. 2012). These levels of maintenance are helpful in establishing maintenance schedules and items. It is also important to establish who is responsible for the maintenance of a facility and when that maintenance should occur (Livingston et al. 1997).

Studies have shown that the post-construction inspection and maintenance of GSI is often inadequate resulting in premature failure (Lord et al. 2008). A 1986 study by Lindsey et al. found that half of infiltration facilities inspected in Maryland were not functioning as designed, and two-thirds needed maintenance. Failing to adequately maintain GSI can result in increased discharge of pollutants downstream, increased risk of flooding, potential public health risk, and unpleasant aesthetics (Livingston et al. 1997). Often times, GSI facilities are constructed and either forgotten about or simply assumed to be working indefinitely by stormwater managers (Blecken et al. 2017). MS4s and stormwater managers must consider the necessary requirements for long-term maintenance before deciding to construct GSI facilities.

\subsection{Conclusion}

As the rate of development continues, it will be critical that the key factors for correct implementation and maintenance of GSI be understood in order to protect public health and the quality of water resources. This will involve a coordinated effort from all involved parties including researchers, regulators, lawmakers, developers, and municipalities. The literature emphasizes that the long-term performance of GSI is highly dependent on the proper construction and subsequent maintenance of facilities (Livingston et al. 1997; Blecken et al. 2017). The proper institutional framework must be in place in order to ensure this proper construction and maintenance. In addition, the critical construction and maintenance items must be understood for each type of GSI facility as well as what design and configuration are most appropriate for specific conditions. The use of GSI is still relatively new and the long-term, watershed-scale effects are still not fully known. However, innovative technologies like these will be imperative to mitigating the effects of urbanization on water resources. 


\section{Identifying Key Factors for the Implementation and Maintenance of Green Stormwater Infrastructure}

\subsection{Introduction}

An important change to the management of stormwater in urban environments has occurred over recent decades. To meet increasing regulations and improve the quality of urban stormwater runoff, municipalities and stormwater managers have shifted to implementing smaller and more spatially distributed ("source-control") best management practices (BMPs) to prevent flooding and improve water quality (Dietz 2007; Zimmer et al. 2007). This change from conventional stormwater management approaches (i.e. detention and retention ponds) has caused stormwater managers, engineers, and contractors to change the way they design, construct, and maintain this fundamental infrastructure.

An important shift in stormwater management practice began in 1972 when amendments to the Federal Water Pollution Control Act set new requirements for controlling discharges of pollutants into the nations waterways. Historically, the focus of stormwater regulations had been on flood control and peak flow mitigation with little focus on water quality (Field and Taruri 2005). These amendments, commonly referred to as the Clean Water Act (CWA), changed that narrative and created regulations centered around water-quality standards including maintaining the chemical, biological and physical integrity of the country's water (Environmental Law Institute 2013). Initially, measures to improve water quality were focused on reducing pollutants from traditional point sources such as effluent from industrial and municipal wastewater discharges (National Research Council 2008). This was primarily achieved through permitting system known as the National Pollutant Discharge Elimination System (NPDES).

As the nation began to see the improvements to water quality due to the NPDES and regulation of point source pollution, the focus shifted to more diffuse, non-point sources like stormwater runoff. The passing of additional amendments to the CWA in 1987 created the Water Quality Act (WQA), directing the EPA to begin regulating stormwater discharges from construction and industrial activities as well as discharges from municipal separate storm sewer systems (MS4s) (National Research Council 2008). The WQA was implemented in a two-phased approach starting in 1990, requiring operators of MS4s located in medium or large incorporated areas to 
obtain NPDES permits to discharge stormwater. The system was expanded in 1999 through the implementation of the Phase II rule, requiring smaller MS4s to obtain permits and meet minimum control measures for improving stormwater runoff quality (US EPA 2005a).

Today, one of the most common minimum control measures used by MS4s to reduce pollutant loads in urban runoff and meet regulatory requirements is through the use of stormwater best management practices (BMPs) (Livingston et al. 1997). The term BMP covers a wide array of activities but can be broadly broken up into two categories, non-structural and structural. Nonstructural practices include activities such as disconnecting impervious surfaces, more stringent development regulations, educational programs, and street sweeping programs (Urbonas 1994). Structural BMPs are constructed stormwater management infrastructure designed to treat on-site runoff and mitigate stormwater problems (Livingston et al. 1997). These BMPs reduce runoff volume and can improve the water quality of runoff through physical removal (e.g. infiltration, settling), filtration, physio-chemical (e.g. adsorption), and biological (e.g. plant uptake) removal processes (Scholes et al. 2008). Structural BMPs are often utilized by MS4s because of their defined pollutant and volume reduction capabilities (Strecker et al. 2001). Structural BMPs are given a variety of names including but not limited to: stormwater control measure (SCM), green infrastructure (GI), and green stormwater infrastructure (GSI). For clarity, green stormwater infrastructure (GSI) will be the term henceforth used in this paper.

A regulatory stipulation of using GSI to meet water quality standards is to "ensure adequate long-term operation and maintenance of controls," meaning local governments and MS4s must put in place programs to ensure the longevity of these systems (US EPA 2005). Many studies have shown that proper construction and subsequent maintenance are critical factors for this longevity (Blecken et al. 2017; Brown and Hunt 2012; Roy-poirier et al. 2010). GSI facilities are more susceptible to problems due to improper construction and maintenance compared to traditional stormwater management facilities (Livingston et al. 1997). The specifics on the appropriate inspection frequency and protocols for the construction and maintenance of these facilities still requires more research. This places MS4s in a precarious position of having to allocate resources to ensure the proper construction, inspection, and maintenance of GSI without having definitive standards in place. 
Previous studies have shown that the maintenance of GSI is often inadequate, affecting the performance and longevity of facilities (Lindsey et al. 1992; Blecken et al. 2017; Flynn et al. 2012). The lack of documentation for well-defined inspection and maintenance protocols for BMPs is one of the most significant barriers facing the implementation of these systems (Houle et al. 2013). In addition, maintenance issues can be more complex compared to traditional stormwater management systems (US EPA 2000; Livingston et al. 1997). This highlights the importance of MS4s implementing comprehensive post-construction inspection and maintenance programs (Lindsey et al. 1992). To accomplish this, the common maintenance problems associated with GSI, as well as necessary frequency, must be understood. In addition, the responsible party for performing this maintenance must be clear for both public and private facilities.

Improper construction, often due to lack of construction oversight, can disproportionately affect the performance of GSI compared to traditional stormwater facilities (Livingston et al. 1997). For example, undersized bioretention bowl capture volumes within a bioretention cell can significantly impact the performance (Brown and Hunt 2011). The unintentional compaction of soils by construction equipment can decrease their infiltrative capacity negatively impacting the performance of GSI that utilize infiltration as a pollutant removal mechanism (Brown and Hunt 2010; Prince George's County 2002). The adequate construction of GSI is therefore dependent on the proper training of contractors, project managers, and construction inspectors to ensure they understand the proper sequencing, construction techniques, and necessary oversight (Livingston et al. 1997; Cosgrove Jr. and Bergstrom 2004).

The swift adoption of GSI around the country has outpaced the requisite research and information necessary to certify their effectiveness. This has caused localities to use information, design guidelines, and implementation protocols that may not be appropriate for the region or local site conditions (Davis et al. 2009). At the same time, the level of training and certification that is required by contractors and inspectors is inconsistent, potentially affecting the quality of construction and long-term functionality of these facilities. Ultimately, the design and implementation of GSI varies across the country making it difficult to determine which construction and maintenance practices are most effective (National Research Council 2008). This speaks to the larger point that the 'correct' application of GSI is dependent on a multitude 
of factors. Implementing GSI requires an intimate knowledge of what facility types and configurations work best for specific site conditions as well as which types succeed within certain institutional frameworks (Livingston et al. 1997; US EPA 2000).

This study concentrates on elucidating the construction factors and maintenance protocols that are critical for the long-term functionality and performance of GSI. GSI facilities to be investigated in this study include bioretention cells, permeable pavement, sand filters, infiltration trenches, and vegetated swales. In order to accomplish this, (1) a review of relevant literature and stormwater manuals from across the country was performed in order to determine the most important maintenance and construction items. In conjunction with this review, (2) inspection and maintenance procedures and datasets from Fairfax County, Virginia were used as a case study illuminating the effectiveness of the County’s GSI program as well as common shortcomings for the GSI of interest. Finally, the differences in the frequencies of deficiencies found due to facility ownership (i.e. public vs. private) were investigated. The purpose of this paper is to evaluate the current state of the construction, inspection, and maintenance protocols associated with GSI in order to inform and provide guidance for the correct implementation and maintenance of these systems.

\subsection{Literature Review: Construction and Maintenance Inspection Guidelines}

\subsubsection{Construction}

The proper construction of GSI is considered a critical factor in determining the long-term effectiveness of a facility (Livingston et al. 1997; Prince George's County 2002; NVSWCD 2017). Poor construction of a GSI will cause premature failure, even for the best-designed facilities (Prince George's County 2002). The construction specifications necessary for the

proper functionality of GSI varies between facility types. However, these specifications are typically similar and are often determined by the design and intended pollutant removal mechanism (i.e. filtration, infiltration, biological) of the facility. Below is a summary of the construction techniques and considerations found in the literature that are most critical to GSI performance. The specific construction techniques ultimately depend on the design of the facility as well as site conditions. 


\subsubsection{Construction Sequencing}

Careful consideration of GSI must be taken while determining construction E\&SC plans and construction sequencing (Flynn et al. 2012). One of the primary concerns of construction affecting GSI is the premature introduction of sediment laden runoff clogging filter media and/or underlying soils (Hunt and Lord 2004; Livingston et al. 1997). It is recommended that the drainage area be completely stabilized before the construction of GSI facilities (PA DEP 2006; NJ DEP 2016). If this is not possible, runoff should be diverted from the facility using diversion berms and typical sediment control practices (VA DEQ 2011a; PA DEP 2006).

\subsubsection{Compaction Avoidance}

Compaction of soils has been shown to negatively affect GSI that utilize infiltration (Lindsey et al. 1986; Brown and Hunt 2010). In order to limit compaction, the location of the facility should be well marked and cordoned off throughout the construction process (NJ DEP 2016). Care should be taken to prevent construction equipment and vehicles from driving over the proposed location of infiltration facilities. If possible, excavation should be performed by an excavator outside the limits of a facility (VA DEQ 2011c). If compaction does occur, it can be alleviated by re-fracturing the soil through tilling (NY DEC 2010; WI DNR 2014).

\subsubsection{Filter Media Installation}

GSI that utilize a filter media include bioretention, sand filters, and infiltration trenches. It is important that mix certificates and other documentation be used to ensure that the filter media meets design specifications before being installed (WSU and PSP 2012). The media should be applied in lifts ranging from 8 to 12 " in order to limit the possibility of compaction (Prince George's County 2002; VA DEQ 2011c). The media may also need to be filled over the design

elevation to account for settling. Lightly watering the media while it is being installed may be performed to encourage natural compaction (Prince George's County 2002; PA DEP 2006).

\subsubsection{Permeable Pavement}

Permeable pavement facilities are unique compared to other GSI facilities in the fact that they require a specific mix and application of a surface pavement layer. These facilities also must be 
able to support design loads from vehicular traffic (ME DEP 2016). Because of these reasons, there are construction considerations specific to permeable pavement systems. In addition to the considerations discussed above, special care must be taken when installing the stone aggregate and filter fabric (VA DEQ 2011). There is a specific mix required for both permeable asphalt and permeable concrete that must be adhered to in order to ensure adequate infiltration rates as well as provide necessary load support (NAPA 2008; NJ DEP 2016b). State department of transportation specifications are typically a convenient way to specify the correct aggregate mix (Ferguson 2006). Ultimately, it is critical to hire a qualified contractor who is experienced, licensed, and bonded to install permeable pavement systems (WSU and PSP 2012; Prince George's County DER 2013).

\subsubsection{Construction Inspection}

First and foremost, the proper institutional framework must be in place to provide proper construction inspection authority, training for GSI construction, and the ability to keep engineers and contractors accountable (Livingston et al. 1997). It is often recommended that inspections be performed before, during, and after construction to ensure that the interpretation by the contractor is consistent with the design of GSI (VA DEQ 2011a). This involves facility-specific checklists being used at the most critical stages of construction. Examples of critical inspection items include infiltration testing, filter media mix composition and installation, pervious pavement/concrete mixes, and checking elevations of key features (VA DEQ 2011; Herrera Environmental Consultants 2013).

The specific effects of improper construction techniques on GSI are still unknown. However, it is clear that the proper construction is critical for the long-term functionality of facilities. In order to ensure this occurs, the important construction considerations for each facility type must be understood by contractors, builders, and inspectors. In addition, the conditions and constraints specific to a site must be understood and acknowledged by all parties involved.

\subsubsection{Maintenance}

Maintenance of GSI is performed to ensure functionality over their life cycle as well as preserve aesthetic qualities (Flynn et al. 2012). Maintenance can typically be broken into different levels 
depending on the type, frequency, and intensity required. Routine maintenance is performed regularly, typically encompassing predictable tasks such as vegetation maintenance or debris removal. Non-routine maintenance is performed more infrequently and is typically in response to facility failures such as clogging or structural repairs. Major maintenance items would pertain to major deficiencies that require partial or complete rebuilds of the facility (Kang et al. 2008; Erickson et al. 2009; Flynn et al. 2012). These levels of maintenance are helpful in establishing maintenance schedules and items. It is also critical to establish who is responsible for the maintenance of a facility and when that maintenance should occur (Livingston et al. 1997). This can be accomplished through requiring a facility maintenance plan that identifies who is responsible for maintenance throughout the facilities life cycle (US EPA 2011). It may also be necessary to establish binding legal agreements between owners and municipalities to ensure proper maintenance is being performed on facilities located on private property (Roy-Poirier et al. 2010).

Many studies have shown that maintenance of GSI is often inadequate, leading to reduced facility performance and longevity (Lindsey et al. 1992; Brown and Hunt 2012; Blecken et al. 2017). Inadequate maintenance can lead to an increased levels of pollutants contained in runoff, increased risk of flooding downstream, as well as diminished aesthetic qualities (US EPA 2016). Field inspections of more than 250 facilities in Maryland, performed by Lindsey, Roberts, and Page (1992), found that in just a couple of years nearly one-third of facilities were not functioning as designed and most needed maintenance. Additionally, a study by Wardynski and Hunt (2012) found that over half of the 41 bioretention facilities inspected in North Carolina had maintenance issues, namely sediment deposition problems. Studies like these illuminate the inherent difficulty for a MS4 to maintain hundreds to thousands of facilities and provide evidence for the need for concise and deliberate maintenance inspection and enforcement programs (Roy-poirier et al. 2010).

The sections below attempt to summarize the most crucial maintenance items for different GSI types. Items are based on the main components of GSI and not specific facility types as many of these facilities contain similar maintenance requirements. 


\subsubsection{Good Housekeeping}

Good housekeeping on its own is one of the six minimum control measures required by MS4s to meet the conditions of NPDES permits (US EPA 2005b). However, good housekeeping can also reduce the maintenance required for GSI and is an important part of maintenance plans (Portland BES 2016). Regularly scheduling trash, debris and sediment removal from a site will reduce the amount of trash, debris and sediment that will need to be removed from a GSI facility. In addition, inspecting the drainage area for signs of erosion and reseeding as needed will reduce the sediment load entering GSI during storm events (Portland Bureau of Environmental Services 2016). Education and training of good housekeeping techniques for reducing/preventing pollutants in runoff is essential to limit the amount of pollutants entering GSI (US EPA 2005b).

\subsubsection{Vegetation Maintenance}

GSI facilities that typically incorporate vegetation include bioretention, vegetated swales, and some sand filters. Regardless of the facility type, vegetation maintenance is typically routine and predictable (Flynn et al.2012). Though the benefits of vegetation are difficult to measure, it is accepted that vegetation provides pollutant removal through biological uptake and is important for the overall function of the facility (Blecken et al. 2017).

Watering is recommended when vegetation is first being established and during periods of drought (Prince George's County 2002; PA DEP 2006). Facilities that incorporate a mulch layer (i.e. bioretention) must have the layer inspected for erosion, floating, and bare spots. It is typical to completely replace the mulch layer every 2 to 3 years (Prince George's County 2002; WSU and PSP 2012). Seasonal pruning and weed removal is necessary for most facilities, especially while establishing vegetation. Finally, facilities that utilize grassed turf should be mowed to maintain a height of 7.6 to $15.2 \mathrm{~cm}$ (3 to 6 inches) during the growing season (NJ DEP 2014).

It is also important to maintain the vegetated areas around GSI in order to ensure the drainage area is stabilized and limit the amount of sediment reaching facilities (PA DEP 2006; VA DEQ 2011c). The vegetation component of GSI should be treated as a typical landscaping feature and should be incorporated into routine maintenance schedules (NY DEC 2010). 


\subsubsection{Filter Media}

GSI often incorporates some kind of filer media with varying mixes of sand, organic matter, and aggregate (Claytor and Schueler 1996). Filter media removes pollutants primarily through a physical process of filtering particulates out of the water (Urbonas 2002). Facilities that typically incorporate filter media include bioretention, sand filters, and infiltration trenches. The most critical maintenance item regarding filters is preventing premature clogging due to excess sediment (Barrett 2003; WSDE 2012). The clogging of media is typically discovered when facility drain times exceed the design drain time (VA DEQ 2011b). For this reason, it is recommended that sediment accumulation be inspected frequently, especially after major storm events (NY DEC 2010; MDE 2000). If clogging is determined to be an issue, the top 5.1 to 7.6 $\mathrm{cm}$ ( 2 to 3 inches) of media may need to be tilled in order to restore the infiltrative capacity (PA DEP 2006; NY DEC 2010). In extreme cases the entire media may need to be replaced in order to restore the functionality of facility (Prince George's County 2002).

\subsubsection{Infiltration Capacity}

GSI that incorporates infiltration as a pollutant removal mechanism is designed to temporarily store runoff and allow it to percolate into underlying soils (Akan 2002). This means that the infiltrative capacity of the soil must be maintained. GSI that can utilize infiltration include bioretention, infiltration trenches, pervious pavement, and vegetated swales. Infiltration facilities are unique in that they offer the greatest runoff reduction capability compared to other practices (VA DEQ 2011a) as well as provide ground water recharge and preserve base flow (Maniquiz et al. 2010).

Ponding water and sediment accumulation are common maintenance issues associated with infiltration facilities (US EPA 1999a). Lindsey et al. (1992) found that inappropriate ponding of water was found in more than half of the infiltration basins inspected. Much like filtration practices, the top 5.1 to $7.6 \mathrm{~cm}$ ( 2 to 3 inches) of soil may need to be tilled/aerated if ponding water becomes an issue (MPCA 2017). For facilities that incorporate a stone layer (i.e. infiltration trenches), the stone may need to be removed and replaced if clogging remains an issue (ME DEP 2016). Infiltration facilities should be inspected regularly for clogging, especially after major storm events (US EPA 1999). 


\subsubsection{Access Requirements}

Anecdotal evidence from maintenance personnel has shown that one of the biggest difficulties in maintaining GSI is just having adequate access to the location of required maintenance (Livingston et al. 1997; Barrett 2003; Flynn et al. 2012). It is highly recommended that some sort of enforceable maintenance agreement be put in place that grants inspection and maintenance personnel access to facilities on private property (WSU and PSP 2012; NY DEC 2010). The design of GSI should keep in mind the need for maintenance access.

\subsubsection{Permeable Pavement}

The most common maintenance issue associated with permeable pavement facilities is the clogging of the pavement surface and/or underlying infiltration bed with sediment (PA DEP 2006; Erickson et al. 2009). The infiltration rate of permeable pavement facilities should be monitored at least annually using a standard infiltration rate method like ASTM C1701 (NJ DEP 2016a; Portland BES 2016; WI DNR 2016). In order to preserve the infiltrative capacity of the facility it is recommended that facilities be vacuum swept at least twice per year (NAPA 2008; Amde and Rogge 2013; NJ DEP 2016b).

Care should be taken when de-icing permeable pavement surfaces. Typically, these surfaces have less snow and ice accumulations compared to traditional pavement (PA DEP 2006; NAPA 2008). However, it may still be necessary to apply deicing compounds such as salt or liquid deice. Sand or ash should never be used as a de-icing agent as these can contribute to clogging of the surface (ME DEP 2016; NAPA 2008). Sediment and debris should be removed as necessary (NY DEC 2010). Perhaps most important is that the owner and/or operator be educated on the proper maintenance and function of these facilities (WSU and PSP 2012). Maintenance frequency and items should be tailored to fit specific site conditions, permeable pavement type and design, and expected sediment loads (NY DEC 2010; VA DEQ 2011).

\subsubsection{Maintenance Inspections}

It is well accepted that regular post-construction inspection of GSI is critical to inform nonroutine maintenance and ensure the long-term functionality of facilities (Brown and Hunt 2012; Field and Taruri 2005; Prince George's County 1999). However, the necessary frequency and 
effective implementation of inspections is still a major question (Houle et al. 2013). Many state manuals recommend annual or biannual inspections of GSI in addition to inspections after major storm events (ranging from 1.3 to $2.54 \mathrm{~cm}$ ) (PA DEP 2006; ME DEP 2016); although, it is not feasible for a MS4 to be able to inspect all GSI in its inventory after a storm event. It is recommended that standardized checklists be used for each type of facility. This will ensure consistency in inspection items and will allow the facility performance to be tracked over time (Livingston et al. 1997).

It is important to keep in mind that inspection costs may be minor when compared to the cost of maintenance (Hunt et al. 2005). Maintenance costs of GSI should be seriously considered prior to construction (Erickson et al. 2009). Ultimately, specific GSI types should not be constructed if the proper institutional support is not in place to ensure the adequate maintenance of these facilities over their life cycle. In order to accomplish this, specifications should emphasize maintainability, specific maintenance items and frequency should be clear and within an enforceable maintenance agreement, the role of government must be clearly established, and the public must be educated and buy in to the importance and function of these systems (Livingston et al. 1997; WSU and PSP 2012).

\subsection{Case Study: Fairfax County's GSI Maintenance Program}

\subsubsection{Introduction}

Fairfax County, VA is a suburb of Washington D.C., covering an area of approximately 1010 $\mathrm{km}^{2}$. (U.S. Census Bureau 2017). With a population of 1,142,888 people and a median household income of $\$ 115,717$, Fairfax is one of the most affluent counties in the U.S. (Fairfax County 2017a). Fairfax has made significant capital investment in their stormwater management program in an effort to meet both the NPDES MS4 permits and the total maximum daily loads (TMDLs) associated with the Chesapeake Bay TMDL (Fairfax County 2017b; US EPA 2010). Part of this program is ensuring the long term operation and maintenance of GSI (Fairfax County DPWES 2017). Fairfax County has predominantly modeled their program for GSI construction and maintenance protocols after the Virginia state stormwater management laws and regulations. Authority to manage GSI comes directly or tangentially through various sections of the Virginia Stormwater Management Act, Erosion and Sediment Control Law, the Chesapeake Bay 
Preservation Act, and the County's MS4 Permit GSI (Fairfax County DPWES 2017). The combination of these laws provide the County with authority to enforce the proper construction and maintenance of GSI facilities.

Having nearly 7,000 stormwater management facilities tracked in their system, including 2,360 of the five GSI types mentioned above, the necessary program investment and implementation towards ensuring adequate functionality is considerable. Table 3.1 below shows the count of each of the five GSI types.

Table 3.1 - Fairfax County GSI facility counts for bioretention (BR), permeable pavement (PP), sand filter (SF), infiltration trench (TR), and vegetated swale (VS)

\begin{tabular}{cccc}
\hline Facility ID & Count & Public & Private \\
\hline Bioretention (BR) & 660 & 104 & 556 \\
Permeable Pavement (PP) & 93 & 77 & 16 \\
Sand Filter (SF) & 238 & 6 & 232 \\
Infiltration Trench (TR) & 1294 & 56 & 1238 \\
Vegetated Swale (VS) & 75 & 47 & 28
\end{tabular}

About one-third of all facilities are public, being inspected and maintained directly by the County's Maintenance and Stormwater Management Division (MSMD). Public facilities are inspected on either an annual or biennial frequency with routine maintenance performed multiple times a year on most facility types. The remaining two-thirds of stormwater management facilities are private facilities that must be maintained by the owner or operator (Fairfax County DPWES 2017). Private facilities are inspected at least once every five years by MSMD to ensure adequate maintenance and functionality. Authority to inspect and require adequate maintenance of private facilities typically comes through Private Maintenance Agreements (PMAs) and local ordinance.

Inspections are performed by certified, third-party inspectors who use unique inspection forms, with pertinent maintenance items, provided by the County, for each facility type. These forms track the condition of the facility and indicate whether or not non-routine maintenance is required. If additional maintenance is considered necessary, MSMD creates work orders for 
public facilities or sends out notifications to private owners to require private facility maintenance.

\subsubsection{Methods}

Inspection and maintenance data sets for GSI were obtained from the County and used to assess the current state of the County's inspection and maintenance programs. Because of the relatively new implementation of the County's construction inspection program, there is very limited data for construction inspections. Therefore, the focus of this case study will be the post-construction inspection and maintenance of GSI. The maintenance data available varied between facility types as well as whether or not a facility was privately or publicly owned and maintained. By reviewing the post-construction inspection data, the typical maintenance problems, as well as how the frequencies of these problems differ between public and private facilities were determined and compared.

\subsubsection{Public and Private Maintenance Data}

Data for publicly owned facilities was extracted from maintenance tracking spreadsheets used by the MSMD to consolidate inspection findings and assign maintenance priorities. The inspection data spans from 2011 to 2017 and includes 891 separate inspections. These spreadsheets included fields (categories) for various maintenance issues for GSI including sediment accumulation, blockages, access issues, debris accumulation, structural problems, erosion, bare spots, inadequate vegetation, cave-ins, and animal holes. Each item was given a yes/no designation by an inspector as to whether or not there was a deficiency. The exact nature or magnitude of the deficiency was not recorded.

Private facility data was obtained through third-party inspection spreadsheets from various consulting firms in which their inspections and correspondence with the County was tracked. Private inspection data spans from 2010 to 2017 and is comprised of over 2,000 individual inspections. From the private inspection spreadsheets, the inspection dates, an indication of whether or not maintenance was needed, and a brief maintenance description was obtained. The maintenance issues associated with private facilities were determined based on the maintenance description assigned. Maintenance items were ultimately categorized similarly to the public 
inspection data as described above. If the description mentioned a category, it was assumed to be found deficient during the inspection. For example, structural issues were assigned if the maintenance description mentioned problems with structures, monitoring wells, spalling, pipe connections, etc. Keyword searches were used in the maintenance description of the inspection reports and were quality controlled to ensure maintenance issues were properly assigned. Table 3.2 shows the maintenance items that were ultimately used to compare public and private facilities.

Table 3.2 - Common maintenance categories used to compare publicly and privately owned facilities

\begin{tabular}{cc}
\hline \multicolumn{2}{c}{ Maintenance Category } \\
\hline Sediment & Erosion \\
Blockage & Bare Spot \\
Debris & Vegetation \\
Structural & Access Issue
\end{tabular}

\subsubsection{Northern Virginia Soil and Water Conservation District Bioretention Study}

In addition to the inspection and maintenance data, an independent study performed on 63 public bioretention facilities by the Northern Virginia Soil and Water Conservation District (NVSWCD) was reviewed and compared to inspection data (NVSWCD 2017). This study involved a more in-depth evaluation of these facilities as compared to typical inspections, and included a topographic survey of the ponding area, a survey of filter media depth, a field measurement of filter media infiltration rates, and an analysis of filter media physical composition. The components above were chosen because of their significant role in the runoff and pollutant reduction capabilities of the facility. Studies have shown that ponding depth, surface area, and filter media depth are critical with regards to the performance of bioretention facilities (Brown and Hunt 2011; Wardynski and Hunt 2012). Improper construction of bioretention cells has also been shown to lead to inadequate ponding, filter media depth, and premature clogging (Brown and Hunt 2012; Wardynski and Hunt 2012). The NVSWCD ultimately found that the deficiencies observed in bioretention facilities in the County were primarily related to inadequate construction, and not insufficient maintenance (NVSWCD 2017). 
For the same 63 facilities from the NVSWCD study, post-construction inspection checklists from the County were obtained and organized into a database comprised of 256 individual inspections ranging from 2008 to 2015. Eighty-seven unique inspection fields were available from these checklists and consolidated to assign a score to a particular inspection. Fairfax County uses a priority scoring system to indicate the severity of a deficiency. For this study, items with a high priority/non-functional score were given a 3 , moderate priority a score of 2 , and low

priority/functional items a score of 1 . Any item found to have no deficiency was assigned a score of 0 . This allowed for the inspector's findings to be quantified and the overall inspection given a score. A higher score indicates a poorer condition of the bioretention facility at the time of that inspection. The results of this analysis were two-fold. First, it illuminated trends of the most frequently occurring and severe maintenance issues associated with publicly maintained bioretention facilities using more detailed inspection data. Second, it allowed the findings from the NVSWCD study to be compared to the County inspection forms to determine whether or not current inspection protocols are sufficient for discovering deficiencies due to improper construction.

\subsection{Results and Discussion}

\subsubsection{Maintenance Deficiency Frequency: Public vs. Private Facilities}

The frequencies of maintenance issues found during inspections for both public and private facilities were determined and compared. The specific deficiencies were categorized based on the type of facility. Table 3.3 reports the percentages of deficiencies for each facility type. Figure 3.1 below graphically show the differences between public and private facilities. 
Table 3.3 - GSI inspection item frequencies (\%) for public versus private facilities reporting the number of inspections and various categories of maintenance deficiencies found during inspection

\begin{tabular}{c|ccccc}
\hline & \multicolumn{5}{|c}{ Public (Private) } \\
\cline { 2 - 6 } Facility ID & Bioretention & $\begin{array}{c}\text { Permeable } \\
\text { Pavement }\end{array}$ & $\begin{array}{c}\text { Sand } \\
\text { Filter }\end{array}$ & $\begin{array}{c}\text { Infiltration } \\
\text { Trench }\end{array}$ & $\begin{array}{c}\text { Vegetated } \\
\text { Swale }\end{array}$ \\
\hline $\begin{array}{c}\text { Number of } \\
\text { Inspections }\end{array}$ & $362(550)$ & $138(6)$ & $25(249)$ & $272(1418)$ & $94(27)$ \\
\hline Sediment & $25.1(5.1)$ & $15.2(83.3)$ & $48.0(43.0)$ & $41.9(34.1)$ & $11.7(3.7)$ \\
Blockage & $16.6(5.5)$ & $10.1(0.0)$ & $24.0(4.8)$ & $18.4(2.8)$ & $20.2(0.0)$ \\
Access Issue & $3.6(0.2)$ & $1.4(0.0)$ & $16.0(16.1)$ & $8.5(0.4)$ & $5.3(0.0)$ \\
Debris & $34.8(5.1)$ & $20.3(66.7)$ & $60.0(33.7)$ & $43.0(11.2)$ & $19.1(3.7)$ \\
Structural & $26.2(17.1)$ & $8.7(33.3)$ & $28.0(43.0)$ & $21.3(26.0)$ & $11.7(44.4)$ \\
Erosion & $28.7(10.4)$ & $2.9(0.0)$ & $8.0(0.0)$ & $8.8(3.1)$ & $9.6(3.7)$ \\
Bare Spot & $31.5(6.2)$ & $2.2(0.0)$ & $20.0(0.0)$ & $8.5(4.9)$ & $18.1(22.2)$ \\
Vegetation & $12.2(36.7)$ & N/A & $8.0(2.4)$ & $1.5(11.6)$ & $9.6(25.9)$
\end{tabular}

\subsubsection{Permeable Pavement}

Figure 3.1(a) below shows the frequency of maintenance issues associated with permeable pavement. The private facility data has a low number of samples (6) and therefore must be viewed cautiously since there are not enough points to establish any definitive trends. More data points were available in the public data, with a total of 138 public inspections used for this analysis. Sediment and debris were the most common issues which follows trends from other research on permeable pavement as clogging due to sediment is often cited as the primary maintenance issue (Amde and Rogge 2013; Putman 2010). Therefore, the importance of good housekeeping of the drainage area around permeable pavement is paramount in limiting the amount of sediment entering these systems. To achieve this, a program may need to increase maintenance frequency based on the sediment loads expected in a particular CDA. 


\subsubsection{Infiltration Trench}

Infiltration trenches were the most numerous GSI type in the County with over 1,200 facilities, providing the most inspection data. A total of 272 public and 1418 private facility inspections were available for analysis. Figure 3.1(b) shows that sediment accumulation was a problem for $34 \%$ of public and $42 \%$ of private facilities. This illustrates the importance of pretreatment devices being installed and maintained properly when utilizing infiltration trenches (US EPA 1999a). The long term effectiveness of infiltration trenches is one of the main concerns with this GSI type. A 1991 study by Lindsey et al. found that 53\% of infiltration trenches were not operating as designed and $36 \%$ were partially or totally clogged. The accumulated debris and sediment found in County facilities could also diminish their conveyance and infiltrative capacity.

\subsubsection{Sand Filters}

As shown by Figure 3.1(c), sand filters had the most consistent maintenance issues between publicly and privately owned facilities. A total of 25 public and 249 private facility inspections were analyzed and again, sediment and debris were the most common issues recorded. The high frequency of sediment and debris accumulation in sand filters points to the potential need for routine maintenance for removal. Clogging and subsequent rejuvenation of filter media is one of the largest maintenance burdens associated with these systems (Barrett 2003). The frequency of maintenance should be based on the expected sediment loads entering a facility. Filter bed material should be inspected frequently to determine whether or not replacement is necessary. It should also be noted that sand filters had the most significant access issues for both public and private facilities (16\% of inspections). This was typically due to locked or jammed access doors. 


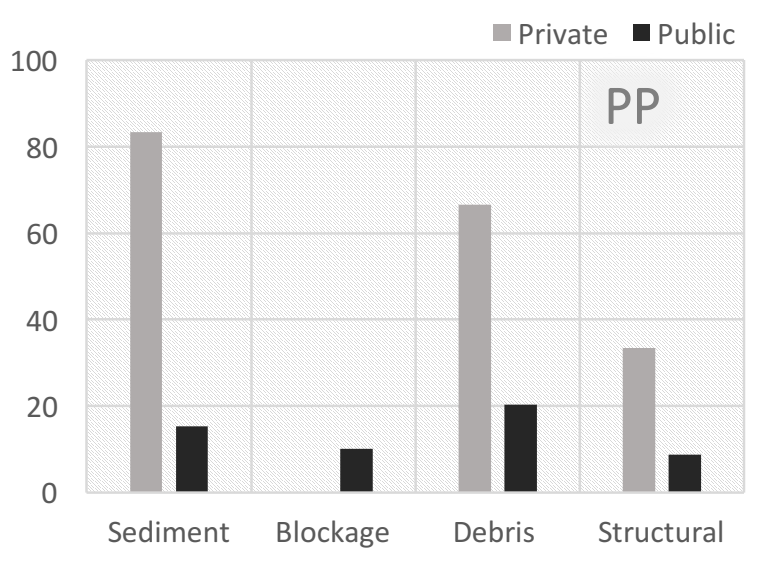

(a)

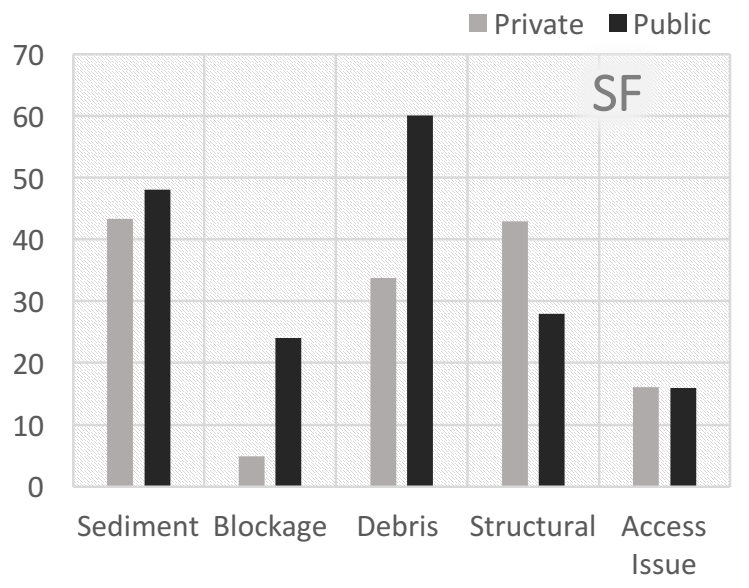

(c)

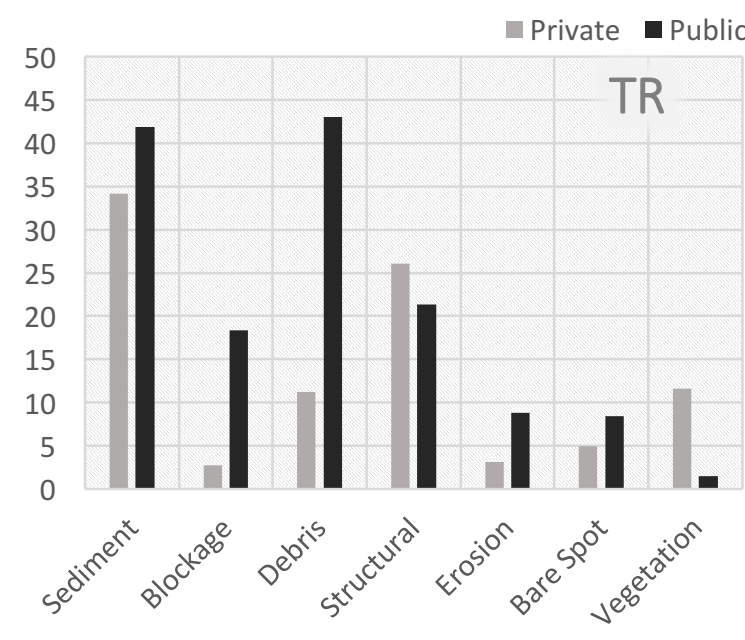

(b)

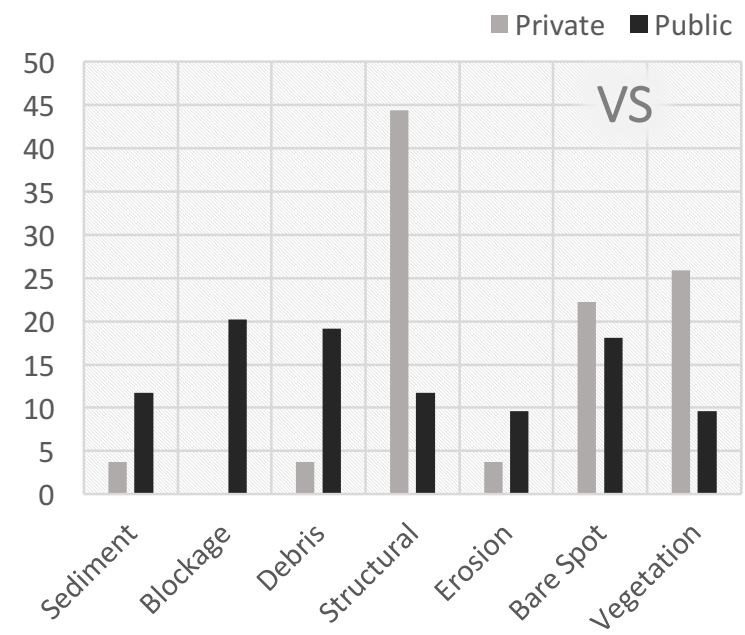

(d)

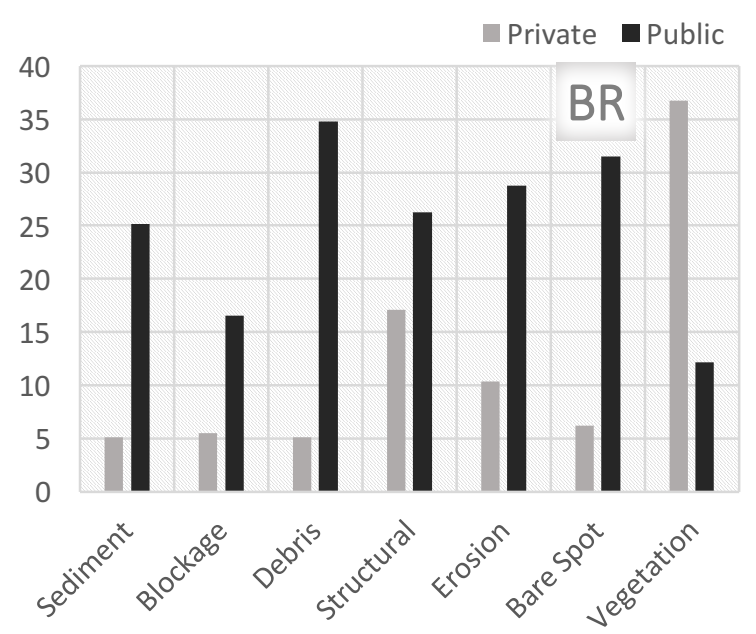

(e)

Figure 3.1 - Percent (\%) of inspection problems reported for (a) permeable pavement (PP), (b) infiltration trench (TR), (c) sand filter (SF), (d) vegetated swale (VS), (e) bioretention (BR) 


\subsubsection{Vegetated Swales}

Vegetated swales comprised the smallest sample sizes of all GSI with 94 public and 27 private facility inspections available. Figure 3.1(d) shows the maintenance item frequencies associated with vegetated swales. The most glaring deficiency are the structural issues associated with private facilities. This can be attributed to 12 of the 27 (44\%) inspections noting missing or damaged check dams. Check dams are important for slowing the flow of water, promoting infiltration, and creating temporary ponding areas all of which improve pollutant removal (US EPA 2004). Overall, vegetated swales had the lowest frequency of maintenance problems of the five types of GSI studied. This could possibly be attributed to the relative simplicity of maintenance items and the County's routine maintenance of these facilities.

\subsubsection{Bioretention}

Figure 3.1(e) shows frequency of deficiencies for each maintenance category for bioretention facilities. There were a total of 362 public and 550 private inspections for bioretention facilities. Sediment and debris accumulation were found to be the most frequent inspection deficiency for public facilities, with $25 \%$ and $35 \%$ respectively. This was much higher than that of private facilities ( $5 \%$ and $5 \%$ respectively). Erosion problems and bare spots were also more frequent for public facilities. Issues with vegetation (either missing, dying, or overgrown) was the major maintenance issue for privately owned facilities, being found in nearly $37 \%$ of facilities.

The differences in maintenance items between public and private bioretention facilities is worth noting and could be attributed to a variety of factors. Perhaps most important would be the variations in the average contributing drainage area (CDA) metrics of public versus private sites. The average drainage area for public bioretention facilities was found to be 0.87 acres compared to 0.54 acres for private. Many public facilities are used in commercial areas in which they would receive runoff from parking lots and large rooftops. The prevalence of these larger structures can have a major impact on the constituents of surface runoff and lead to potentially more erosive flows containing more sediment and debris.

\subsubsection{Discussion}


The data presented above shows that the frequency of maintenance deficiencies associated with GSI can vary depending on whether or not a facility was publically or privately owned. The exact reasons for this variability is still unknown. The local site conditions for a particular facility could play a large role in the frequency and type of deficiencies. Public and private properties typically have different land uses which can partially explain the differences seen above.

Another factor that would affect the frequency of deficiencies is based on the stakeholder responsible for the maintenance of the facility. Public GSI facilities are under the care of the County's MSMD who routinely maintain them (Fairfax County DPWES 2017). On the other hand, private facilities are privately maintained by their owner, some of which may not even be aware they have a facility located on their property. Previous studies have shown that many private facility owners do not adequately maintain their GSI (Livingston et al. 1997). This may be due to a variety of reasons including the lack of knowledge, resources, or incentive to routinely maintain these facilities. This disparity in routine maintenance likely plays a major role in the types and frequency of deficiencies found as well as the overall lifespan of facilities.

Generally speaking, the most common maintenance issue found during inspections was the accumulation of sediment and debris. This is not surprising, as many studies and state stormwater manuals emphasize the negative effects sediment can have on GSI. The clogging of filter media, native soils, and aggregate has been shown to be one of the main reasons of failure (Putman 2010; Bergman et al. 2011; Virahsawmy et al. 2014). This fact should be emphasized to inspectors, maintenance crews, and facility owners. In addition, this finding confirms the need for pretreatment on the influent side of these facilities to increase lifespan and long-term efficient operation.

\subsubsection{Bioretention Facilities: Comparing Inspection Findings}

Data from handwritten County bioretention inspection forms was consolidated and compared to the findings of the NVSWCD study. By summing the scores of each of the 87 bioretention checklist items from the 256 NVSWCD individual inspection forms, a more succinct view of the most common issues associated with bioretention facilities are shown. The complete list of the 87 checklist items can be found in Appendix A (Figure A.1). The use of a scoring system 
allowed the frequency and magnitude of deficiencies to be quantified. With 256 inspections and the highest score for an individual item being a 3, the highest possible total score would be 768 . Figure 3.2 below shows the 10 highest scoring items associated with public bioretention facilities. The condition of plants within the ponding area was the highest scoring item, partially due to the fact that this item had the most non-functional priority ratings. This does not necessarily point to decreased function of facilities, but it does show that missing/unhealthy vegetation is one of the most common maintenance issues associated with bioretention. Erosion at the inflow points was the next highest scoring item potentially relating to the erosion problems seen on the berms and the sediment deposition seen within the ponding area. The 10 most frequently occurring inspection items (independent of score) are shown in Figure 3.3. Overall, the inspection items were ranked similarly to the highest scoring items. Bare spots on the berm of bioretention facilities was found to be the most frequent deficiency being noted on $14 \%$ of inspection forms.

The 256 inspection forms used are just a small fraction of the total handwritten forms archived by the County. However, this inspection data is stored as scanned forms into individual project folders and does not lend itself to large-scale data analysis. This analysis shows the potential value in recording and consolidating inspection data into a database to be used by MS4s or other governing bodies. If Fairfax County was able to store all inspection data into a database, valuable insight on the trends of maintenance problems for individual facilities, as well as entire facility types, could be obtained. This would help the County see common deficiencies in its stormwater infrastructure and potentially see correlations with other factors such as site conditions, CDA, or ownership type. For example, if a pattern of sediment deposition within a bioretention facility was noted, proactive measures could be taken to investigate the drainage area for potential sources of sediment. By having more comprehensive data available, it would highlight any differences in facility deficiencies between publicly and privately maintained facilities. 


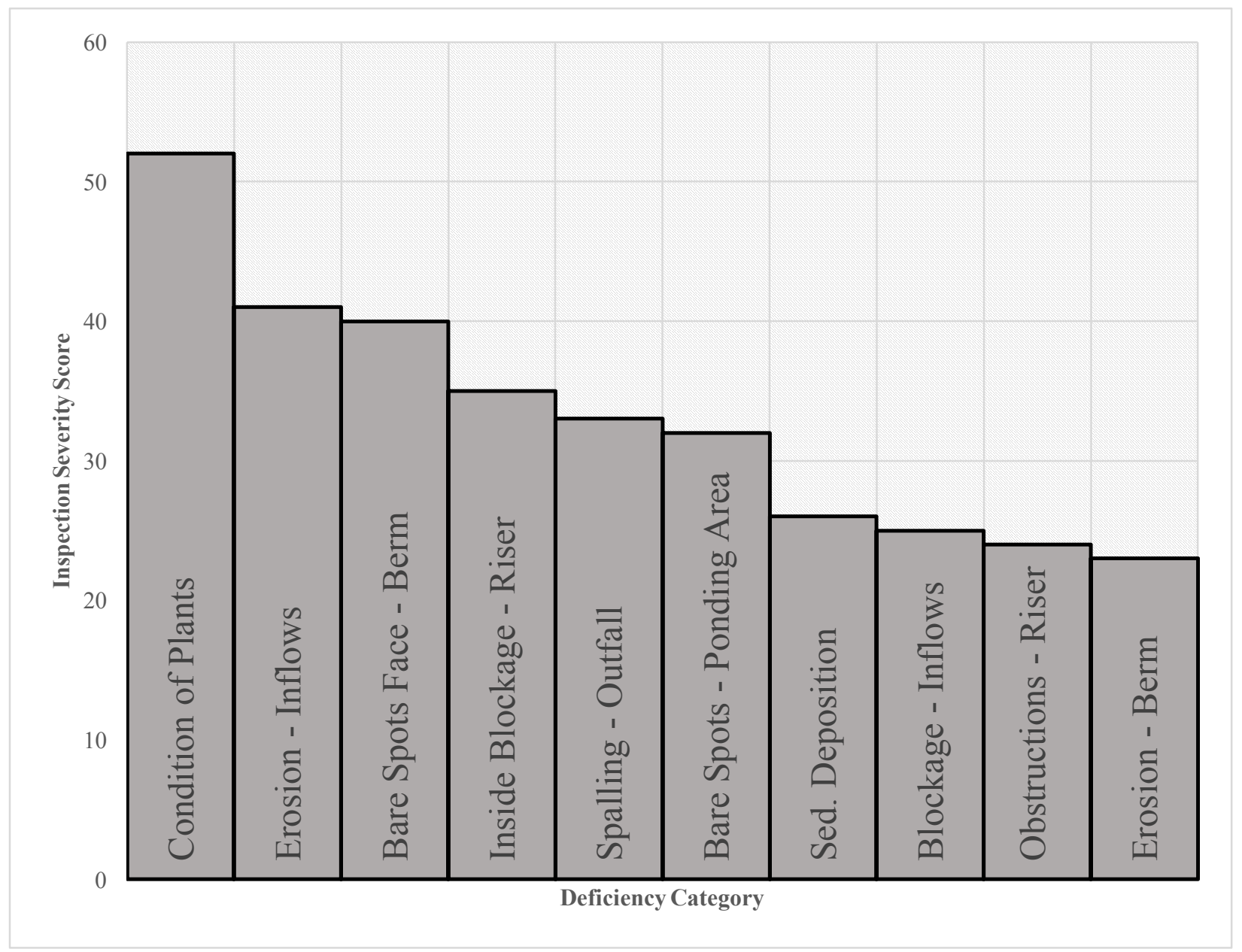

Figure 3.2 - Inspection severity scores for inspection items from Fairfax County bioretention checklists 


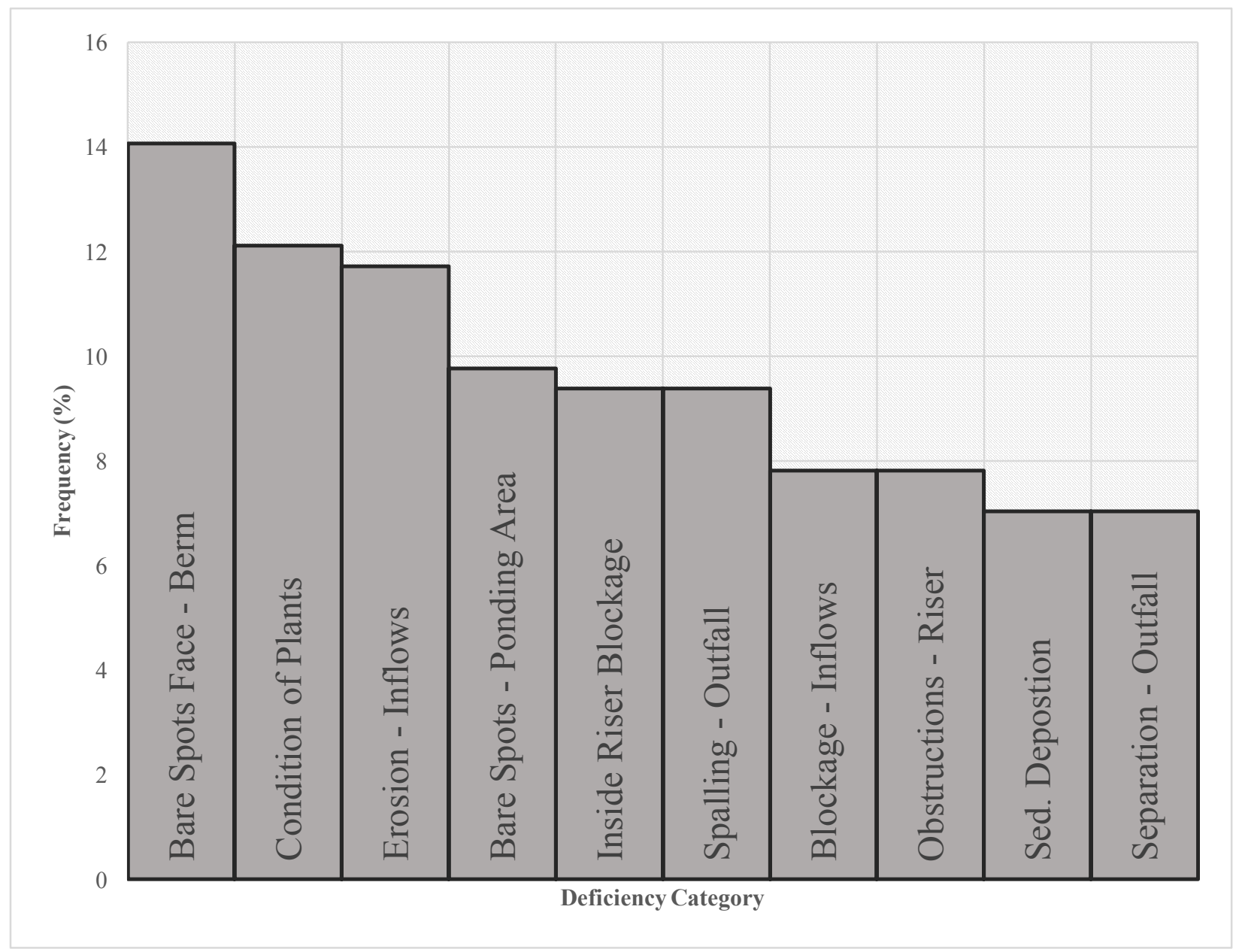

Figure 3.3 - Most frequently occurring inspection items from Fairfax County bioretention checklists

\subsubsection{Correlation Between Inspection and NVSWCD Scores}

The NVSWCD assigned each of the 63 facilities studied a score based on the condition of various components determined to be critical to bioretention performance. The highest scoring facilities were asserted to be the most defective and in need of restorative maintenance. To determine if standard County inspections would predict these deficiencies, the County's inspection form closest in time to the NVSWCD inspection date was used as a comparison. The majority of inspection forms were found to be within a few months of the NVSWCD inspection. By plotting the scores from the County inspections against the scores assigned by the NVSWCD, a rudimentary comparison can be drawn to determine if current inspection protocols are discovering critical deficiencies as found by the NVSWCD study. Figure 3.4 below shows the results of the analysis. 


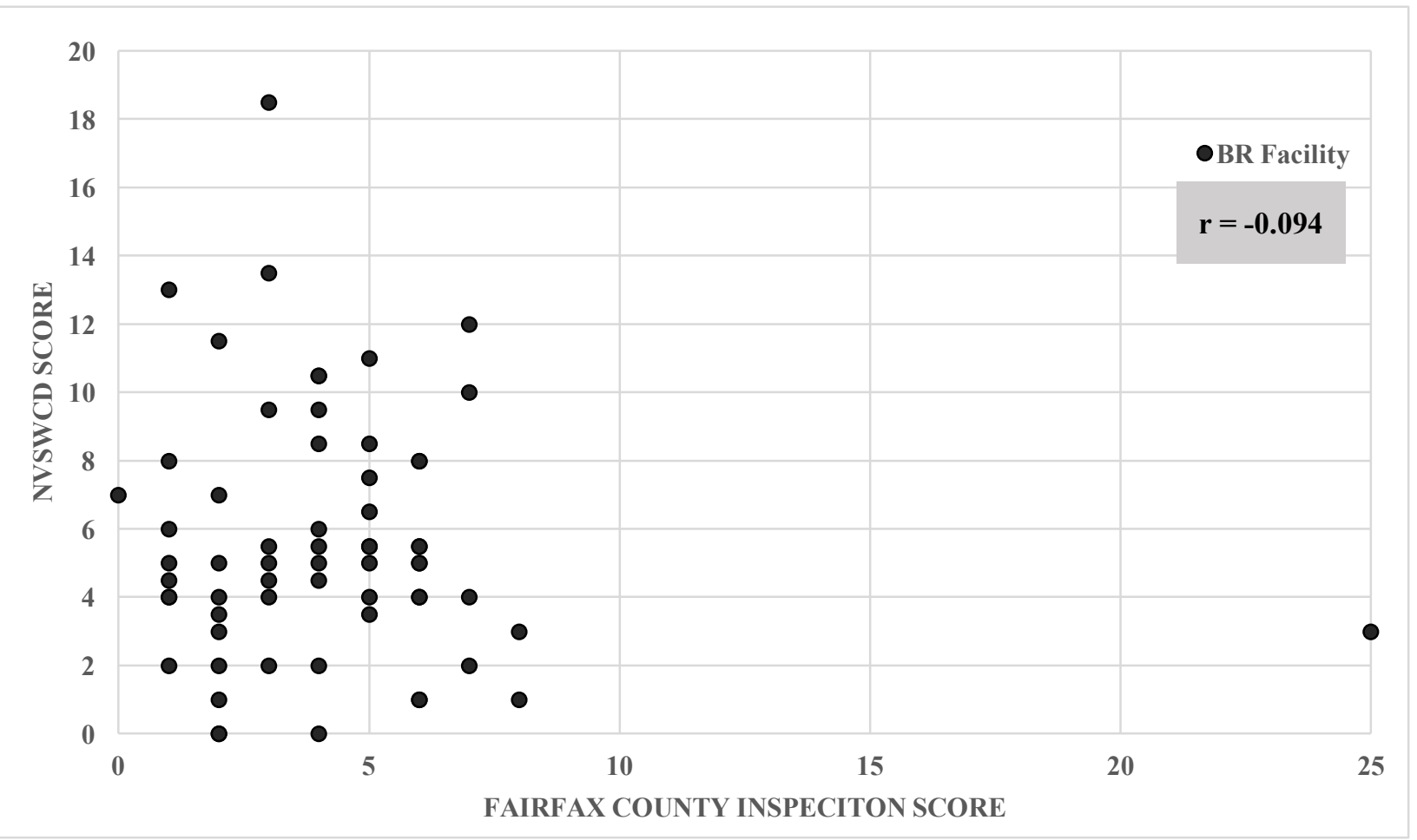

Figure 3.4 - Determining correlation between County inspection scores and NVSWCD scores

Pearson's correlation coefficient was used to determine whether or not there was a correlation between the score based on the County inspections and the score assigned by the NVSWCD. This would show if the facilities with high scores in the NVSWCD study would also have a high score based on the routine inspections performed by the County. Based on a r value of -0.094 , there is almost no correlation between the two scores. This shows that County inspections are not finding the same deficiencies that the more thorough NVSWCD study found (NVSWCD 2017). The NVSWCD focused on ponding area, filter media depth, and infiltration rates because these have been shown to be important to the runoff reduction and pollutant removal ability of bioretention cells. In addition to this, these components can be highly affected by, and are dependent on, proper construction. This analysis shows that the current inspection forms/protocols do not tell the full story about inadequacies during the construction process, instead being focused on the more superficial characteristics of these facilities. This highlights the importance of MS4s and stormwater managers focusing on proper construction inspections to ensure facilities are initially being built correctly and then creating thoughtful post-construction inspection forms to ensure facilities continue to function as designed. Much of Fairfax County's inspection of bioretention facilities is visual, focusing on sediment accumulation, signs of 
erosion, and structural deficiencies. More in-depth inspections may be required to better assess the functionality of GSI. For example, this may mean the inclusion of maintenance inspection items such as measuring filter media depth and infiltration rates for bioretention facilities.

\subsection{Conclusions and Implications}

This research shows the importance of defined, proactive construction, maintenance, and inspection programs for MS4s that choose to implement GSI. MS4s must first consider the ultimate goals/reasons on why they are installing GSI as well as honestly assess their ability to ensure proper construction and maintenance. The coordination necessary to confirm adequate construction and the subsequent post-construction inspection and maintenance is substantial. A framework must be put in place to make sure governmental agencies are effectively tracking and coordinating maintenance and inspection in order to "ensure adequate long-term operation and maintenance of controls,"(US EPA 2005). Making this more difficult is the fact that there is not one ultimate or definitive standard to construct and maintain GSI. Though there is relative continuity across the country on the generally accepted specifications and protocols, the specific implementation of GSI must be done thoughtfully.

The necessary construction protocols are variable depending on the conditions of the site and the specifics of the design. Construction of GSI should be evaluated on a case-by-case basis with all parties involved knowing the necessary sequencing and inspection items. Though GSI facilities are relatively simple in design, their functionality is sensitive to oversight and carelessness during construction. The type and frequency of post-construction maintenance required is variable and a function of the site conditions, expected pollutant loads entering a facility, and specific design components as much as the facility type itself. MS4s should consider these variables, as well as who is responsible for the maintenance, when determining appropriate maintenance items, frequency, and protocols. The frequency of deficiencies found for GSI could also be a function of the frequency of routine maintenance performed, which is often determined by the party responsible for maintenance. MS4s and stormwater managers should actively assess the effectiveness of private and public facility maintenance programs (as these are often different) to determine whether or not they need to take over or change private facility maintenance protocols. 
This research also shows the value of MS4s and local governments consolidating maintenance and construction data into a database to help identify trends in deficiencies for specific facilities, as well as facility types. Over just a few years of thoroughly tracking and storing GSI data, valuable insight into the effectiveness and maintenance requirements of certain GSI types, specific to the region and local site conditions, could be gained. This would help inform future decision making on the types of GSI that should be used for specific site conditions, their necessary maintenance and inspection frequencies, and what facility types are the most costeffective when comparing construction/maintenance costs to the pollutant removal credits gained.

Based on the NVSWCD report, deficiencies found in bioretention facilities were mostly attributed to construction inadequacies and not due to insufficient maintenance (NVSWCD 2017). This emphasizes the importance of properly constructing GSI the first time to extend the effectiveness of these facilities and reduce future maintenance burdens. Comparing the NVSWCD study to County inspections revealed that current checklists and inspection protocols used in Fairfax County are missing important items. Post-construction inspections should emphasize the components most critical to runoff reduction and pollutant removal and not just aesthetic qualities. For GSI, this typically involves inspecting the infiltration rates of soils, aggregate, and filter media as well as ensuring ponding depths, critical slopes, and filter media depths are to design specifications. These more involved inspection items will naturally be more expensive, so perhaps they should be emphasized during the first few years of a facilities' lifecycle. This will also help determine whether or not facilities have been constructed properly. Surrogate indicators of facility performance (such as sediment accumulation and ponding water) can then be used more reliably for future inspections. 


\section{Conclusion}

\subsection{Implications}

As the percentage of humans living in urbanized areas continues to increase, it will be critically important to continue to develop innovative technologies to mitigate the impact of urbanization and human development on the environment. Rapid human population growth will inherently put more and more pressure on the natural environment as we continue to use vital resources and discharge pollutants. In the face of an uncertain global climate, water supply and water quality may be the defining issues in the decades to come. Part of the solution will be to develop intricate and complex stormwater management systems in order to mimic predevelopment conditions to the greatest extent practicable. This will help minimize pollutants reaching waterways as well as supporting groundwater recharge by promoting infiltration into native soils. GSI will not be the only part of the stormwater systems of the future. It will have to be strategically used in tandem with traditional stormwater systems as well as innovative land development techniques such as low impact development (LID).

This research supports the importance of proper construction and maintenance when implementing GSI. In order to accomplish this, the key factors for performance must be identified for each facility type and thoroughly understood through the construction and maintenance processes. Care must be taken with GSI as it is more sensitive to inadequate construction and maintenance compared to traditional stormwater management facilities. This research also shows that the necessary construction and maintenance protocols can vary depending on a multitude of factors including site-conditions, facility design specifications, and institutional support. Proper construction sequencing and timing of construction inspections must be determined for each new facility. The necessary frequency of post-construction inspection and maintenance must also be assessed on a case-by-case basis. Inspections should focus on the critical components for performance for each facility type and not necessarily aesthetic qualities.

Finally, this research demonstrates the potentially substantial value recording inspection and maintenance data into database can have. Creating a database in this fashion could provide MS4s will valuable information as well as improve the cost-effectiveness of implementing these systems. By thoroughly inspecting and recording data during construction, the quality of 
construction will improve and the measurements of key design elements can then be used during post-construction inspections. A database of post-construction inspection and maintenance data will illuminate trends for individual facilities as well as GSI types as a whole. This will help inform future decision making by MS4s and determine which facility types are most effective for its particular circumstances.

\subsection{Future Work}

Future research on the construction and maintenance of GSI should focus on further evaluating the variability of deficiencies and maintenance required due to differences in site conditions (i.e. CDA and \% imperviousness), adequacy of construction, variability in design specifications, as well as the frequency of routine maintenance. This would help define the most cost-effective GSI over its lifetime, and protocols necessary to ensure its longevity, specific to a certain geographic area and/or the institutional capacity of a MS4. It would also be revealing to compare the implementation of GSI between different municipalities and cities to evaluate differences in the numbers of GSI facilities, protocols for constructing and maintaining public and private facilities, frequencies of maintenance, and capital costs incurred to run these programs. The effects of improper construction and maintenance have yet to be fully quantified and studied. That being said, incorporating monitoring studies in tandem with this could provide valuable results. By constructing one GSI facility stringently to specifications and violating key protocols while constructing another, the specific effects of inadequate construction could begin to be quantified. For example, constructing a bioretention facility with less than $50 \%$ filter media depth, or subjecting it to excessive compaction, and comparing its pollutant removal efficiency to a properly constructed facility. The effects of maintenance could be studied in the same manner. For example, one could take two facilities that were identically constructed and adequately maintain one and neglect the other. Future works like these would significantly improve the understanding behind the necessary construction and maintenance protocols centered around GSI. 


\section{References}

Akan, A Osman. 2002. "Modified Rational Method for Sizing Infiltration Structures." Canadian Journal of Civil Engineering 29(4): 539-42.

http://www.nrcresearchpress.com/doi/10.1139/102-038.

Amde, A.M., and S. Rogge. 2013. "Development of High Quality Pervious Concrete Specifications for Maryland Conditions.” (February): 111.

Barbosa, A. E., J. N. Fernandes, and L. M. David. 2012. "Key Issues for Sustainable Urban Stormwater Management." Water Research 46(20): 6787-98.

http://dx.doi.org/10.1016/j.watres.2012.05.029.

Barrett, Michael E. 2003. "Performance, Cost, and Maintenance Requirements of Austin Sand Filters.” Journal of Water Resources Planning and Management 129(3): 234-42. http://ascelibrary.org/doi/abs/10.1061/(ASCE)0733-9496(2003)129:3(234).

Bergman, M. et al. 2011. "Evaluation of Two Stormwater Infiltration Trenches in Central Copenhagen after 15 Years of Operation." Water Science and Technology 63(10): 2279-86.

Bilotta, G.S., and R.E. Brazier. 2008. "Understanding the Influence of Suspended Solids on Water Quality and Aquatic Biota." Water Research 42(12): 2849-61. https://www.sciencedirect.com/science/article/pii/S0043135408001401 (April 23, 2018).

Blecken, Godecke Tobias et al. 2017. "Stormwater Control Measure (SCM) Maintenance Considerations to Ensure Designed Functionality." Urban Water Journal 14(3): 278-90. http://dx.doi.org/10.1080/1573062X.2015.1111913.

Brabec, Elizabeth, Stacey Schulte, and Paul L. Richards. 2002. "Impervious Surfaces and Water Quality : A Review of Current Literature and Its Implications for Watershed Planning Impervious Surfaces and Water Quality : A Review of Current Literature and Its Implications.” Journal of Planning Literature 16(MAY 2002): 499-514.

Brown, Robert A., and William F. Hunt. 2010. "Impacts of Construction Activity on Bioretention Performance." Journal of Hydrologic Engineering 15 (6): 386-94. doi:10.1061/(ASCE)HE.1943-5584.0000165.

Brown, Robert A., and William F. Hunt. 2011. "Impacts of Media Depth on Effluent Water Quality and Hydrologic Performance of Undersized Bioretention Cells." Journal of Irrigation and Drainage Engineering 137 (3): 132-43. doi:10.1061/(ASCE)IR.19434774.0000167.

Brown, Robert A., and William F. Hunt. 2012. "Improving Bioretention/biofiltration Performance with Restorative Maintenance.” Water Science and Technology 65 (2): 36167. doi:10.2166/wst.2012.860.

Carpenter, S R et al. 1998. "Nonpoint Pollution of Surface Waters With Phosphorus and Nitrogen.” Ecological Applications 8(3): 559-68. http://www.esajournals.org/doi/abs/10.1890/10510761\%281998\%29008\%5B0559\%3ANPOSWW\%5D2.0.CO\%3B2.

Claytor, Richard A., and Thomas R. Schueler. 1996. "Design of Stormwater Filtering Systems." 
Environmental Protection (December 1996): 220. http://pittsburghpermaculture.org/wpcontent/uploads/2010/04/stormwater_filtration_system_design.pdf.

Cosgrove Jr., James, and Jeremiah Bergstrom. 2004. "Design and Construction of Biofiltration Basins: Lessons Learned." : 1-10.

Davis, Allen P., William F. Hunt, Robert G. Traver, and Michael Clar. 2009. "Bioretention Technology: Overview of Current Practice and Future Needs." Journal of Environmental Engineering 135(3): 109-17. http://ascelibrary.org/doi/10.1061/\%28ASCE\%2907339372\%282009\%29135\%3A3\%28109\%29.

Dietz, Michael E. 2007. "Low Impact Development Practices: A Review of Current Research and Recommendations for Future Directions." Water, Air, and Soil Pollution 186(1-4): 351-63.

Environmental Law Institute. 2013. "State Constraints: State-Imposed Limitations on the Authority of Agencies to Regulate Waters Beyond the Scope of the Federal Clean Water Act." : 240. https://www.eli.org/sites/default/files/eli-pubs/d23-04.pdf.

EPA. 2016. "Operation and Maintenance of Green Infrastructure Receiving Runoff from Roads and Parking Lots: Technical Memorandum.” (September). https://www.epa.gov/sites/production/files/201611/documents/final_gi_maintenance_508.pdf.

Erickson, Andrew J et al. 2009. "Maintenance of Stormwater BMPs." World Environmental and Water Resources Congress 2009: Great Rivers, May 17-21, 2009 342: 135. http://link.aip.org/link/?ASC/342/135/1.

Erickson, Andrew J, Peter T Weiss, and C Bruce Wilson. 2009. "Survey of Stormwater BMP Maintenance Practices." (January 2015): 1-6.

Fairfax County. 2017a. "Demographic Reports 2017 Fairfax County Board of Supervisors."

Fairfax County. 2017b. "FY 2018 Adopted Budget Summary."

Fairfax County DPWES (Fairfax County Department of Public Works and Environmental Services). 2017. "Post-Construction Stormwater Inspection and Maintenance Policies and Procedures," no. April.

Ferguson, Bruce K. 2006. "Porous Pavements : The Making of Progress in Technology and Design." International Conference on Concrete Block Paving: 11-16.

Ferguson, Bruce K. 2010. "Porous Pavements in North America : Experience and Importance Revêtements Poreux En Amérique Du Nord : Expérience et Importance.” : 1-6.

Field, Richard, and Anthony N. Taruri. 2005. "The Use of Best Management Practices (BMPs) in Urban Watersheds." (September): 268.

Flynn, K. M., B. W. Linkous, and M. T. Buechter. 2012. "Operation and Maintenance Assessment for Structural Stormwater BMPs." World Environmental and Water Resources Congress 2012: Crossing Boundaries: 3662-73.

http://ascelibrary.org/doi/abs/10.1061/9780784412312.368. 
Herrera Environmental Consultants. 2013. WESTERN WASHINGTON LOW IMPACT DEVELOPMENT (LID) OPERATION AND MAINTENANCE (O\&M).

Houle, James J. et al. 2013. "Comparison of Maintenance Cost , Labor Demands , and System Performance for LID and Conventional Stormwater Management.” (July): 932-38.

Hunt, W. F., W. G. Lord, and J. T. Smith. 2005. "Determining BMP Inspection and Maintenance Costs for Structural BMPs in North Carolina." Impacts of Global Climate Change: 1-6. http://ascelibrary.org/doi/abs/10.1061/40792(173)173.

Hunt, W, and W Lord. 2004. "Bioretention Performance, Design, Construction, and Maintenance.” North Carolina Cooperative Extension Service.

James, L Allan. 2003. "Non-Point Source Pollution and the Clean Water Act: Policy Problems and Professional Prospects." Environmental Protection (126): 1-8.

Kang, By Joo-hyon, Peter T Weiss, C Bruce Wilson, and John S Gulliver. 2008. "Maintenance of Stormwater BMPs: Frequency, Effort and Cost.” Stormwater 9(December): 18-28.

Leopold, Luna. 1968. "Hydrology for Urban Land Planning - A Guidebook on the Hydrologic Effects of Urban Land Use." Geological Survey Circular, U.S. Department of the Interior.

Lindsey, Greg, Les Roberts, and William Page. 1986. "Inpspection and Maintenance of Infiltration Facilities." 47: 481-86.

Lindsey, Greg, Les Roberts, and William Page. 1992. "Maintenance of Stormwater BMPs in Four Maryland Counties: A Status Report." Journal of Soil and Water Conservation Society 47(5): 417-22.

Livingston H., Eric, Earl Shaver, and Joseph Skupien J. 1997. “Operation, Maintenance, and Management of Stormwater Management Systems."

Lord, W G, W F Hunt, Environmental, and Asce Water Resources Institute of. 2008.

"Stormwater BMP Maintenance and Certification Program in North Carolina, USA." World Environmental and Water Resources Congress 2008: Ahupua'a 316.

http://www.scopus.com/inward/record.url?eid=2-s2.0-

79251481084\&partnerID=40\&md5=86fd79f2c726e9b7b989aad6655587ef.

ME DEP (Maine Department of Environmental Protection). 2016. “Maine Stormwater Management Design Manual” III (January). www.maine.gov/dep.

Maniquiz, Marla C., So-Young Lee, and Lee-Hyung Kim. 2010. "Long-Term Monitoring of Infiltration Trench for Nonpoint Source Pollution Control." Water, Air, \& Soil Pollution 212 (1-4): 13-26. doi:10.1007/s11270-009-0318-z.

MDE (Maryland Department of the Environment). 2000. "Maryland Stormwater Design Manual, Appendix B.3, Construction Spec's for Bioretention, Filters, and Open Channels," 10.

MPCA (Minnesota Pollution Control Agency). 2017. "Minnesota Stormwater Manual." https://stormwater.pca.state.mn.us/index.php?title=Main_Page.

NAPA (National Asphalt Pavement Association). 2008. "Porous Asphalt Pavements for Stormwater Management," 24. 
National Research Council. 2008. "Urban Stormwater Management in the United States." : 587. https://books.google.com/books?id=JB9YTu9SoXcC\&pgis=1.

NJ DEP (New Jersey Department of Environmental Protection). 2014. "New Jersey Stormwater Best Management Practices Manual: Chapter 9.12 Standard for Grass Swales," no. September: 1-16.

NJ DEP (New Jersey Department of Environmental Protection). 2016a. "New Jersey Stormwater Best Management Practices Manual: Chapter 9.1 Standard for Bioretention Systems." Quantum 1 (2008): 2009-10.

NJ DEP (New Jersey Department of Environmental Protection). 2016b. "New Jersey Stormwater Best Management Practices Manual: Chapter 9.7 Standard for Pervious Paving Systems," no. November 2016: 1159-65.

NY DEC (New York State Department of Environmental Conservation). 2010. "New York State Stormwater Management Design Manual," no. August: 624.

NVSWCD (Northern Virginia Soil and Water Conservation District). 2017. "Evaluation of Publicly Maintained Bioretention Facilities” 25 (1): 30-33. doi:10.1002/ejoc.201200111.

O.Pfrang, Edward. 2013. "Permeable Pavements." : 1-2. http://www.dublincity.ie/sites/default/files/content/WaterWasteEnvironment/WasteWater/D rainage/GreaterDublinStrategicDrainageStudy/Documents/Vol 3 - Permeable Pavements.pdf.

Paul, Meyer, and Judy Meyer. 2001. "Streams in the Urban Landscape." Ecology 32(2001): 33365.

PA DEP (Pennsylvania Department of Environmental Protection). 2006. "Pennsylvania Stormwater Best Management Practices Manual,” 642. doi:363-0300-002.

Portland BES (Portland Bureau of Environmental Services). 2016. "Cit of Portland Stormwater Management Manual,” no. Augsust 2016: 1-4. doi:10.1016/B978-1-85617-567-8.50011-1.

Prince George's County. 1999. “Low-Impact Development Design Strategies: An Integrated Design Approach." (June): 150. http:/www.co.pg.md.us/DocumentCenter/Home/View/86.

Prince George’s County. 2002. "Bioretention Manual.” Programs \& Planning Division.

Prince George’s County DER. 2013. “Guidelines for Permeable Pavement.” (7): 1-33.

Putman, BJ. 2010. "Field Performance of Porous Pavements in South Carolina." Proceedings of the 2010 South Carolina Water Resources Conference (2007).

Roy-poirier, Audrey, Pascale Champagne, A M Asce, and Yves Filion. 2010. "Review of Bioretention System Research and Design : Past, Present, and Future.” 136(September): 878-89.

Scholes, Lian, D. Michael Revitt, and J. Bryan Ellis. 2008. "A Systematic Approach for the Comparative Assessment of Stormwater Pollutant Removal Potentials.” Journal of Environmental Management 88(3): 467-78. 
Shirke, Nilesh Arjun, and Scott Shuler. 2009. "Cleaning Porous Pavements Using a Reverse Flush Process.” Journal of Transportation Engineering 135(11): 832-38.

Strecker, By Eric W et al. 2001. "Determining Urban Storm Water BMP Effectiveness." 127(June): 144-49.

U.S. Census Bureau. 2017. "U.S. Census Bureau QuickFacts: Fairfax County, Virginia." https://www.census.gov/quickfacts/fact/table/fairfaxcountyvirginia,US/LND110210\#viewto p (March 22, 2018).

Urbonas, Ben. 1994. “ASSESSMENT OF STORMWATER BMPs AND THEIR TECHNOLOGY.” Sci. Tech 29(12): 347-53.

Urbonas. 2002. "Stormwater Sand Filter Sizing and Design A Unit Operations Approach.” : 119.

US EPA (United States Enviornmental Protection Agency). 2000. "Low Impact Development (LID): A Literature Review." (October): 41. https://nepis.epa.gov/Exe/ZyPDF.cgi/P1001B6V.PDF?Dockey=P1001B6V.PDF.

US EPA (United States Enviornmental Protection Agency). 1993. "Urban Runoff Pollution Prevention and Control Planning." : 175.

US EPA (United States Enviornmental Protection Agency). 1999a. "Storm Water Technology Fact Sheet." (EPA 832-F-99-048): 7. http://nepis.epa.gov/.

US EPA (United States Enviornmental Protection Agency). 1999b. "Storm Water Technology Fact Sheet - Porous Pavement." : 7.

US EPA (United States Enviornmental Protection Agency). 1999c. "Storm Water Technology Fact Sheet Vegetated Swales.” (EPA 832-F-99-048): 7. http://nepis.epa.gov/.

US EPA (United States Enviornmental Protection Agency). 2000. "Low Impact Development (LID): A Literature Review." (October): 41.

https://nepis.epa.gov/Exe/ZyPDF.cgi/P1001B6V.PDF?Dockey=P1001B6V.PDF.

US EPA (United States Enviornmental Protection Agency). 2004. "Stormwater Best Management Practice Design Guide Volume 2 Vegetative Biofilters." The US Environmental ... 2(September). https://swap.stanford.edu/20120112212400/http://www.epa.gov/nrmrl/pubs/600r04121/600r 04121a.pdf.

US EPA (United States Enviornmental Protection Agency). 2005a. "National Management Measures to Control Nonpoint Source Pollution from Urban Areas.” (November): 518.

US EPA (United States Enviornmental Protection Agency). 2005b. "Stormwater Phase II Final Rule Overview." : 2-4. http://www.epa.gov/npdes/pubs/fact2-0.pdf.

US EPA (United States Enviornmental Protection Agency). 2005c. "Stormwater Phase II Final Rule Post-Construction Runoff Control Minimum Control Measure Stormwater Phase II Final Rule Fact Sheet Series What Is Required?" : 0-2.

US EPA (United States Enviornmental Protection Agency). 2010. “Chesapeake Bay Tmdl 
Executive Summary." : 1-14.

US EPA (United States Enviornmental Protection Agency). 2011. "Summary of State Stormwater Standards." : 144.

US EPA (United States Enviornmental Protection Agency). 2016. "MS4 Permits: Compendium of Clean, Specific \&amp; Measurable Permitting Examples." (November). https://www.epa.gov/sites/production/files/2017-

01/documents/final_compendium_intro_document_508.pdf.

VA DCR (Virginia Department of Conservation and Recreation). 1999. "Virginia Stormwater Management Handbook Volume I" I: 619.

http://www.deq.virginia.gov/Portals/0/DEQ/Water/Publications/HndbkVolumeI.pdf.

VA DEQ (Virginia Department of Environmental Quality). 2011a. "DESIGN SPECIFICATION No . 8 INFILTRATION PRACTICES," no. 8: 1-22.

VA DEQ (Virginia Department of Environmental Quality). 2011b. "Virginia DEQ Stormwater Design Specification No. 12, Filtering Practices, Version 1.9, March 1, 2011 ” 8 (8): 1-22.

VA DEQ (Virginia Department of Environmental Quality). 2011c. "Virginia DEQ Stormwater Design Specification No. 9, Bioretention, Version 1.9, March 1, 2011," no. 9: 54. http://vwrrc.vt.edu/swc/NonPBMPSpecsMarch11/VASWMBMPSpec9BIORETENTION.ht ml\%5Cnhttp://www.vwrrc.vt.edu/swc/documents/2013/DEQ BMP Spec No 9_BIORETENTION_FinalDraft_v1-9_03012011.pdf.

VA DEQ. 2011 (Virginia Department of Environmental Quality). "Virginia DEQ Stormwater Design Specification No. 7, Permeable Pavement, Version 1.8, March 1, 2011," no. 7: 25. http://vwrrc.vt.edu/swc/NonPBMPSpecsMarch11/VASWMBMPSpec7PERMEABLEPAV EMENT.html.

Virahsawmy, Harry K., Michael J. Stewardson, Geoff Vietz, and Tim D. Fletcher. 2014. "Factors That Affect the Hydraulic Performance of Raingardens: Implications for Design and Maintenance." Water Science and Technology 69(5): 982-88.

Walsh, Christopher J. et al. 2005. "The Urban Stream Syndrome: Current Knowledge and the Search for a Cure." Journal of the North American Benthological Society 24(3): 706-23. http://www.journals.uchicago.edu/doi/10.1899/04-028.1.

Wardynski, Brad J., and William F. Hunt. 2012. "Are Bioretention Cells Being Installed Per Design Standards in North Carolina? A Field Study." Journal of Environmental Engineering 138(12): 1210-17. http://ascelibrary.org/doi/10.1061/\%28ASCE\%29EE.19437870.0000575 .

Washington State Department of Ecology Water Quality. 2012. "Stormwater Management Manual for Western Washington August 2012.” 30(12): 1039.

WI DNR (Wisconsin Department of Natural Resources). 2016. "Wisconsin Department of Natural Resources Conservation Practice Standard," no. 151. 
WI DNR (Wisconsin Department of Natural Resources). 2014. "Bioretention for Infiltration (1004).” dnr.wi.gov/topic/stormwater/documents/Bioretention1004.pdf.

Wolman, MG, and AP Schick. 1967. "Effects of Construction on Fluvial Sediment, Urban and Suburban Areas of Mary $\neg$ Land." Research3 (Second Quarter 1967) 3(2). https://books.google.ca/books?hl=en\&lr=\&id=kTSBAAAAQBAJ\&oi=fnd\&pg=PT140\&dq $=$ wolman $+1967+$ sediment\&ots $=$ KhTw_7J2u-\&sig=Vm1h5517ESrr-d8xd9id1EAmkME.

WSU, PSP. 2012. "Low Impact Development Technical Guidance Manual for Puget Sound.” (December). http://www.psp.wa.gov/downloads/LID/20121221_LIDmanual_FINAL_secure.pdf.

Zimmer, C A, I W Heathcote, H R Whiteley, and H. Schroter. 2007. "Low-Impact-Development Practices for Stormwater: Implications for Urban Hydrology." Canadian Water Resources Journal 32(3): 193-212. http://www.tandfonline.com/doi/abs/10.4296/cwrj3203193. 


\section{Appendix A - Fairfax Bioretention Inspection Checklist Items}

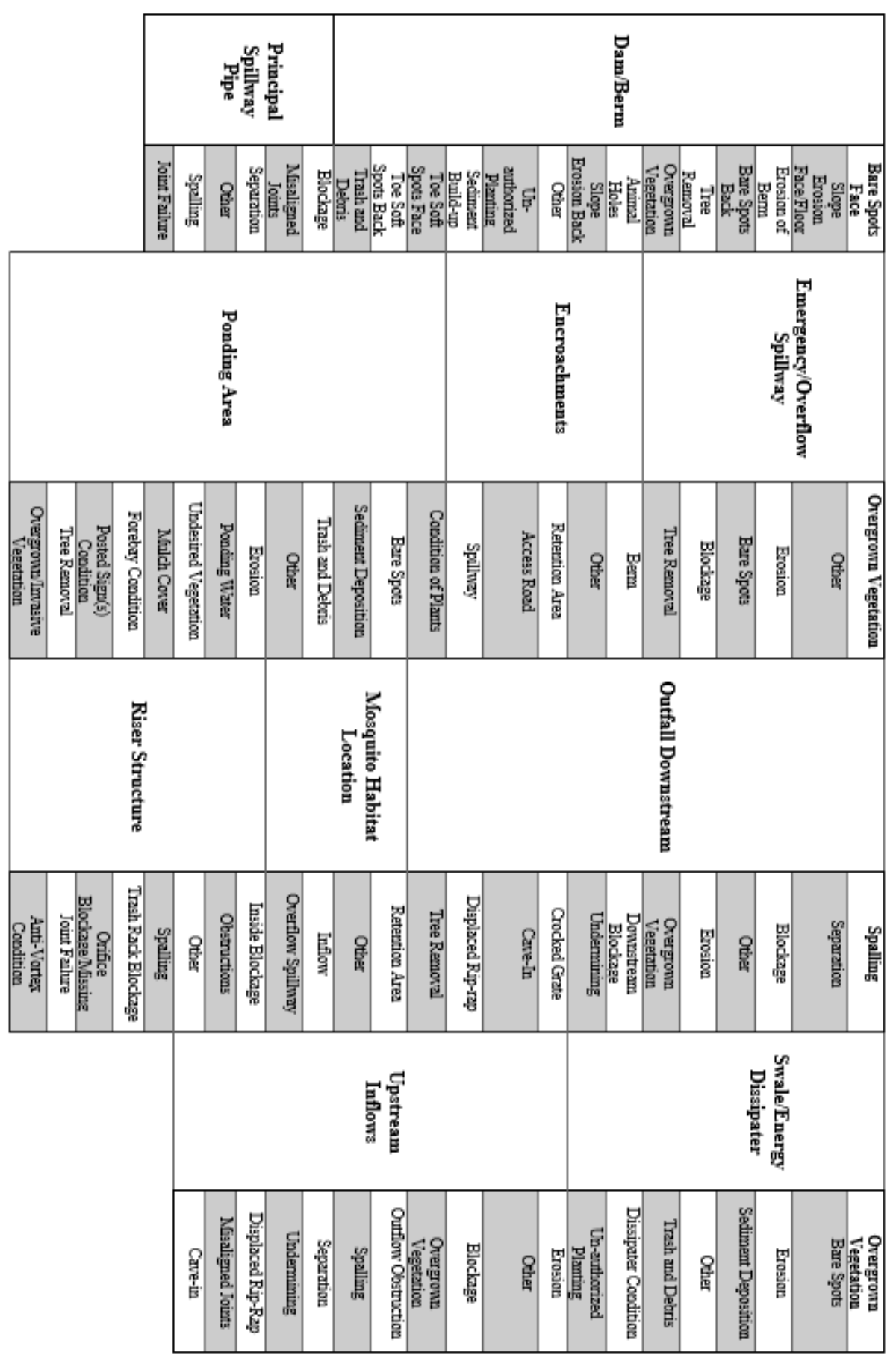

Figure A.1. Bioretention inspection checklist components and their inspection items (87 items total) 